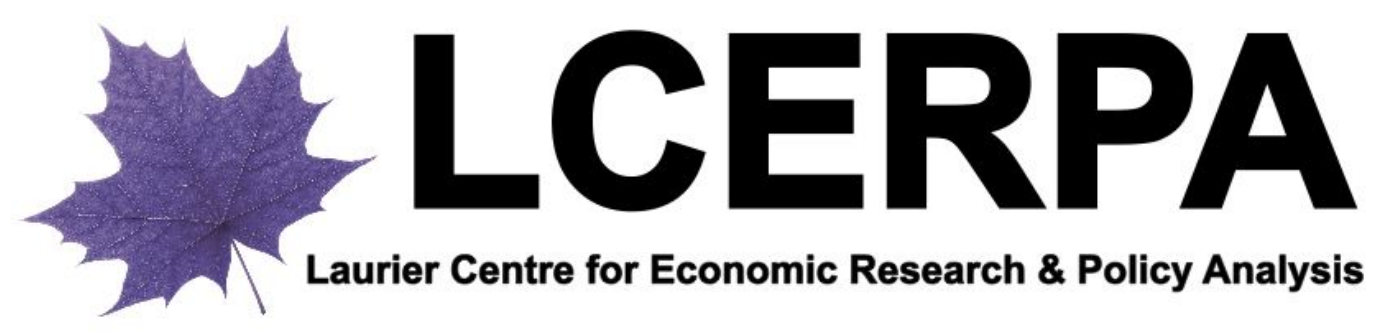

LCERPA Working Paper No. 2017-9

December 2017

\title{
Tat will tell: Tattoos and time preferences
}

\author{
Bradley J. Ruffle, \\ Department of Economics, Wilfrid Laurier University, \\ and \\ Anne Wilson, \\ Department of Psychology, Wilfrid Laurier University
}




\title{
Tat will tell: \\ Tattoos and time preferences
}

\author{
Bradley J. Ruffle ${ }^{1}$ \\ Anne Wilson \\ Department of Economics \\ Department of Psychology \\ Wilfrid Laurier University \\ Waterloo, Ontario \\ Canada
}

December 2017

\begin{abstract}
:
Forty percent of Americans under the age of 40 have at least one tattoo. Yet survey and experimental evidence suggests that the tattooed are viewed negatively and may face discrimination in the labor market and in commercial transactions. In view of the potentially adverse economic consequences of a tattoo, the decision to get one may be regarded as shortsighted and impulsive. We collect numerous measures of time preferences and impulsivity of tattooed and non-tattooed subjects and find broad-ranging and robust evidence that those with tattoos, especially visible ones, are more short-sighted and impulsive than the non-tattooed. Almost nothing mitigates these results, neither the motive for the tattoo, nor the time contemplated before getting tattooed, nor the time elapsed since the most recent tattoo. Even the expressed intention to get a(nother) tattoo predicts increased short-sightedness and helps to pin down the direction of causality between tattoos and short-sightedness.
\end{abstract}

Keywords: experimental economics, tattoo, time preferences, impulsivity.

JEL codes: C91, Z10.

\footnotetext{
${ }^{1}$ This paper benefited from helpful comments from Jeff Chan, Ananish Chaudhuri, Miguel Fonseca, Jonas Fooken, Brit Grosskopf, Alex Krumer, Peter Matthews, Joniada Milla, William Morrison, Philip Oreopoulos, Justin Smith and seminar participants at numerous conferences and departmental seminars. Kaylee Boulton, Ashley Howard and Jordan Kafka provided excellent research assistance. We thank the Laurier Centre for Economic Research \& Policy Analysis (LCERPA) for funding.
} 


\section{Introduction}

We show that tattooed individuals, especially those with visible tattoos, are more short-sighted and impulsive than non-tattooed individuals. These findings are highly robust and supported by an incentivized time-preferences experiment, numerous self-report behaviors in the financial, health and social domains and a well-known measure of impulsivity. Almost nothing mitigates these results: regardless of the motive for getting a tattoo, the time contemplated before getting one's first tattoo or the time elapsed since one's last tattoo, those with hidden tattoos and especially visible ones are more impulsive and less future-oriented than the non-tattooed. The lone exception is women with only hidden tattoos: they are no more present-oriented or impulsive than nontattooed women. Even the stated intention to get a(nother) tattoo within the coming year predicts short-sightedness, both among those already tattooed and the non-tattooed. This finding helps to establish the direction of causality between tattoos and short-sightedness: tattoos do not lead to short-sightedness, rather they are an expression of short-sightedness.

The rise in popularity of tattoos constitutes one of the most significant cultural trends in the West. A mere two generations ago, tattoos were largely reserved for criminals, sailors and circus freaks (see Drimmer 1985). Today, 40\% of Americans aged 26-40 have at least one tattoo. ${ }^{2}$ The embrace of tattoos among younger generations may be understood as a fashion trend, though its results are markedly more permanent than most fads. Further, tattooing is a fashion choice with potentially long-lasting implications for employability, earnings and career success. Survey evidence suggests that the $40+$ generation - individuals who grew up when tattoos were primarily the realm of criminals and misfits - have been slower to accept their ubiquity. Although tattoos are becoming less predictive over time of deviant behavior as they become more commonplace (see Swami et al. 2016), stereotypes of the tattooed have not dissipated as quickly. People, especially those from the $40+$ generation, continue to associate tattoos with a spate of negative traits, including deviancy, dishonesty and a lack of trustworthiness.

Since positions of power (e.g., employers, managers, business associates) are often occupied by this $40+$ generation, tattooed individuals' economic outcomes rest with those who regard them negatively and with suspicion. Indeed, Doleac and Stein (2013) present compelling evidence that whites with a wrist tattoo are less trusted and face discrimination of a similar

\footnotetext{
${ }^{2}$ Reported by Statistic Brain based on August 2015 survey conducted by Pew Research Center, http://www.statisticbrain.com/tattoo-statistics/
} 
magnitude to African Americans in commercial transactions. In terms of employment opportunities, York College of Pennsylvania (2013) conducted a national random survey of 401 human resource professionals, asking them to identify the qualities that are "the best way[s] not to get hired for a job.” In response, 60.2\% of the sample indicated a “visible tattoo”. Among its advice for making a good impression in a job interview, Vault.com (a company that provides career information and employer rankings) encourages job candidates to hide their tattoos with clothing and dark colors. ${ }^{3}$ Brallier et al. (2011) show that after having seen an applicant's resume and photograph, restaurant managers prefer to hire non-tattooed male and female servers than their tattooed counterparts.

Tattooing can thus be seen as a relatively puzzling behavior from an economic perspective. The choice to get a visible tattoo can be viewed as the willing affixation of a visible stigma to one's identity. A person weighs the desire to get a tattoo with the projected long-term economic disadvantage of navigating a workplace in which many of their 40+ employers could discriminate against them on the basis of stereotypes. In this respect, the tattoo decision represents a classic intertemporal tradeoff, where immediate desires and benefits are weighed against future benefits and costs. Because of the (relative) permanence of tattoos, a decision to get one (made in the present) possesses the potential to influence distant future outcomes more than virtually any other aesthetic or fashion choice. ${ }^{4}$ Thus, younger individuals pursuing a career who disregard these widely held negative stereotypes among their bosses and potential employers and choose nonetheless to get a tattoo may be revealing short-sightedness and a lack of future orientation.

Our paper is the first to examine the relationship between time preferences and tattoos. We construct a unique dataset that covers numerous facets of tattoos with the goal of comparing the time preferences and impulsivity of the tattooed and non-tattooed. Our dependent measures include an incentivized experiment measuring time preferences, numerous self-report questions on shortsighted behaviors across different domains and the cognitive reflection task (Frederick 2005), a well-known measure of impulsivity. In total, 1104 American users on Amazon Mechanical Turk

\footnotetext{
${ }^{3}$ Specifically, their advice for men includes, "While tattoos and body art are gaining mainstream acceptance, avoid drawing attention to these embellishments. If you have tattoos anywhere on your upper body, avoid the white shirt and instead go for a light color that will prevent anyone from being able to see the tattoos should you remove your suit coat for any reason. Also keep your sleeves down if you have tattoos on your forearms.” For women, they write, "If you have tattoos on your arms or back, wear long sleeves and a darker shirt that will not leave your tattoos visible."

${ }^{4}$ Tattoo removal is possible, but expensive, painful and time-consuming, typically requiring between six and 12 treatments before the tattoo fully disappears (The Record 2012). Tattoos and plastic surgery are comparable in terms of their relative permanence.
} 
(MTurk) completed our 30-minute study. Seven-hundred eighty-one participants reported having no tattoo, 255 have one or more tattoos, all of which can be readily hidden with clothing, and the remaining 68 have at least one visible tattoo (e.g., face, neck, hands). In addition to the number and location of tattoos of each respondent, we also elicit their views on the prevalence and acceptability of tattoos; their reasons for getting each of their tattoos; how long they contemplated their first tattoo; the time elapsed since their last tattoo; and whether they intend to get a first or another tattoo in the coming year. Combined with the short-sightedness and impulsivity measures, our dataset permits us to explore in detail the robustness of our findings to various aspects of tattooing and to test different directions of causality. In particular, we present compelling evidence that short-sightedness predisposes people to get tattoos.

Do those who choose to get a (visible) tattoo, despite its permanence and potentially adverse consequences in the labor market and interpersonal exchanges more generally, not care about their image or what others think of them or do they overestimate the normativeness of tattoos in society? We present evidence that the tattooed care about what others think of them just as much as the non-tattooed, but that they overestimate the prevalence and degree of acceptance of tattoos in society at large.

A growing literature compares the characteristics and perceptions of the tattooed with those of the non-tattooed. In line with the theoretical reasoning that underlies our hypotheses regarding the short-sightedness of tattoos, numerous authors have found that the tattooed are negatively perceived (see Swami and Furnham 2007, Doleac and Stein 2013, and Lane 2014 for a survey); employers prefer to hire the non-tattooed (e.g., Brallier et al. 2011); and consumers prefer to do business with the non-tattooed (e.g., Baumann et al. 2016), although tattooed individuals actually exhibit higher trust and are more willing to work with tattooed salespersons than those without tattoos (Arndt and Glassman 2012).

Many earlier papers find that the tattooed and non-tattooed differ along a number of characteristics. For example, the tattooed are more likely to be unaffiliated with any religion, to have done jail time and recreational drugs (Laumann and Derick 2006) and possess a greater need for a sense of uniqueness (Tiggemann and Golder 2006). More recently, Swami et al. (2016) suggest that the mainstreaming of tattoos has flattened any previous demographic or socioeconomic differences, resulting in the increasing similarity of tattooed and non-tattooed adults. They find that the tattooed are no different in their disposition toward ethical and social 
risks, attentional and non-planning impulsivity and boredom proneness. The few significant differences the authors do uncover have small or negligible magnitudes. French et al. (2016) employ a U.S. and an Australian dataset from national longitudinal surveys that each include a single, binary-response question about whether the respondent has a tattoo. The tattooed report higher rates of unemployment and lower earnings than the non-tattooed. However, once the authors control for educational attainment, social status, occupational, lifestyle and health-related characteristics, the differences become small and nonsignificant. Dillingh et al. (2016) develop a detailed questionnaire on tattoos and piercings that was combined in 2013 with a longitudinal panel of Dutch individuals that includes data on employment, income, health and social life from 2007/82013. The authors find that having a tattoo in the current or previous year is unrelated to the current year's income, but that the likelihood of being employed is lower for the tattooed. Moreover, having a tattoo is correlated with lower educational attainment and lower scores on physical and mental health.

While lower educational attainment may be interpreted as evidence of short-sightedness, none of these papers explicitly estimates the time preferences of the tattooed and non-tattooed. Our paper offers several distinct measures of time preferences using varied methods and across different domains, thereby allowing us to draw robust conclusions.

The next section describes the methods and procedures in detail. Section 3 presents the results and accompanying empirical analysis. In section 4, we subject our main findings to several robustness checks. Section 5 tests causal direction and various explanations for our findings, and shows that the tattooed overestimate the normativeness of tattoos in society. Section 6 concludes.

\section{Methods}

\subsection{Experimental and Survey Design}

We recruited registered Amazon Mechanical Turk (MTurk) users to participate in our 30-minute study. The recruitment notice made no mention of tattoos and was relatively nondescript, indicating simply that "we [the researchers] are interested in the decisions and judgements people make in settings not unlike those encountered in everyday life.”

The study consists of three incentivized experiments followed by an extensive survey. The first incentivized experiment elicits subjects' time preferences and is summarized in Table 1. In each of the ten pairs, each subject chooses between Option A and Option B. Option A remains the 
same throughout all ten pairs: the payment of \$1 USD in 18 hours. Option B pays an exponentially increasing amount across the pairs in three weeks. In Pair 1, Option B also pays \$1 USD, like Option A. Thus, most subjects are likely to prefer Option A in order to receive the $\$ 1$ sooner. Pair 2 already poses a dilemma for subjects since the payment in Option B increases to $\$ 1.05$. Those who prefer Option B are relatively future-oriented and have a comparatively low rate of discount. If $\$ 1.05$ is insufficient to convince the subject to switch to Option B, Pair 3 increases the payment to $\$ 1.10$, Pair 4 to $\$ 1.20$ and so forth. By Pairs 9 and 10, the subject compares $\$ 1$ in 18 hours (Option A) to $\$ 2.20$ and $\$ 2.50$ in 3 weeks, respectively (Option B). One of the ten pairs is randomly chosen and the subject's chosen option for this pair determines his payment. Our dependent measure is the pair at which the subject switches from the lower, more immediate payment (Option A) to the larger, more temporally distant one (Option B). The later the switching pair, the more impatient or present-oriented the subject is. ${ }^{5}$ We hypothesize that tattooed subjects, particularly visibly tattooed ones, will switch at a later pair on average than the non-tattooed subjects.

Next, subjects participated in two consecutive incentivized tasks that evaluate their honesty (part of a different project and not reported here), followed by an extensive questionnaire composed of the following intermingled varieties of questions: i) self-report behaviors reflecting far-sightedness in the financial, health and social domains; ii) four cognitive-reflection-task questions (Frederick 2005, Thomson and Oppenheimer 2016) used to evaluate subjects' impulsivity; iii) the typical spate of socio-demographic questions. Finally, the study concludes with a detailed questionnaire on tattoos and attitudes toward tattoos.

Recognizing that our incentivized elicitation task is but one (commonly used) method to measure time preferences and focuses on a specific trade-off between time and money, we sought to develop other measures of short-sightedness. Inspired by Weber et al. (2002) who devised domain-specific questions for assessing risk perceptions and behaviors, we crafted a series of questions to evaluate subjects' time horizons in the domains of financial, health and social decisions. For the financial domain, we composed three questions about the respondents' saving for retirement, tendency to make late credit-card payments, and ability to manage their finances and debt. ${ }^{6}$ Our measures of short-sightedness in the health domain consist of four questions about

\footnotetext{
${ }^{5}$ The Appendix displays the experiment as seen by the MTurk subjects. Coller and Williams (1999) developed the original experiment.

${ }^{6}$ All three questions as well as the questions for the health and social domains appear in the Appendix.
} 
the tendency to overeat to the point of not feeling well, exercise frequency, alcohol consumption and smoking behavior. For the social domain, we created three questions. One is a general question about the respondents' desire to have a good time socially even at the expense of their future. The other two questions are specific to social media posts. Because online posts may be thought of as virtually permanent and viewed by many, their effects can be long-lasting. At least anecdotally, new social media realities have resulted in some individuals being called out for inappropriate online behavior, sometimes from the relatively distant past. ${ }^{7}$ In this same vein, Enriquez (2013) refers to online behavior as a “digital tattoo" for its permanent implications. We ask respondents two questions about how likely they are on a ten-point scale to post: i) personal or private information, ii) online statements or opinions that may be controversial. Regular engagement in these behaviors can be viewed as a form of social short-sightedness.

Frederick (2005) developed the cognitive-reflection task (CRT), three questions designed to test subjects' ability to overcome the intuitive but incorrect answer in order to think through the problem to arrive at the correct answer. Poor performance on the CRT has come to be interpreted as an indication of impulsiveness and predicts a wide range of behaviors, including low trust (Corgnet et al. 2016), susceptibility to the conjunction fallacy (Oechssler et al. 2009), the baserate fallacy and other cognitive biases that involve a correct solution (Hoppe and Kusterer 2011). Most relevant for our study, Frederick (2005) and Oechssler et al. (2009) both find that subjects with higher CRT scores are more likely than low-CRT subjects to choose the later, larger reward over the more immediate, smaller reward.

Because the decision to get a permanent-ink tattoo, particularly a visible tattoo, may have been made impulsively with little thought given to future employment consequences, we hypothesize that a tattoo will be associated with fewer correctly answered CRT questions.

The widespread use of the CRT in academic studies, including those on MTurk, means that many have become familiar with the questions. We took several measures to combat this. First, we disguised two of the original three questions by changing both the numbers and the context (e.g., instead of the prices of a bat and ball, ours involves a fast-food vendor's costs of a hamburger and fries combo meal). Second, we also include a version of a newer, less familiar,

\footnotetext{
${ }^{7}$ Examples include the resignations of New Hampshire state Rep. Robert Fisher and Liberal Party candidate for member of the Canadian parliament, Ala Buzreba. The former was found to be the creator of the misogynistic Reddit forum "The Red Pill”, while the latter had posted offensive tweets as a teenager.
} 
fourth CRT question introduced by Thomson and Oppenheimer (2016). ${ }^{8}$ Finally, for each CRT question, we asked subjects at the end of the survey whether they had previously seen the question, thereby allowing us to control for familiarity when evaluating their CRT performance.

Our questionnaire concludes with a detailed portion on tattoos. For each tattooed subject, we learn how many tattoos they have in total; followed by separate questions for how many can be readily hidden with clothing and how many are visible; on which body parts they have tattoos; the motives for getting the hidden and visible tattoos; how long they contemplated their first tattoo; when they got their most recent tattoo; whether they have removed or considered removing any tattoos; and how likely they are to get a tattoo within the next year. For the non-tattooed, we also ask this latter question in addition to questions about how much thought they've given to getting a tattoo and the considerations relevant to their choice not to get one.

\subsection{Procedures}

Upon completion of the experiment, a flat payment of \$1.25 USD was credited to each participant's MTurk account and one of the ten pairs from the time-preferences experiment was independently and randomly selected. The option chosen by the subject for the randomly selected pair determined the amount and timing of this additional payment. The payment from the two honesty experiments (not reported here) was always made within 18 hours of completion, along with the time-preferences payment if Option A was selected for the randomly chosen pair; otherwise, the amount from Option B was deposited in the subject's account three weeks later.

One noteworthy feature of our time-preferences experiment that is commonplace although by no means ubiquitous is the front-end delay associated with payment of Option A. Instead of offering the $\$ 1$ payment immediately, we incorporated an 18-hour delay in order to generate variance in our dependent measure by avoiding the well-documented and overwhelming preference for immediate smaller rewards over larger distant ones (see, e.g., Thaler, 1981; Horowitz 1991 for experimental evidence on immediacy effects) and to equalize the perceived risk of non-payment (see Coller and Williams, 1999; Harrison et al. 2002), which may be particularly relevant in online experiments in which the researchers are anonymous vis-à-vis the participants.

\footnotetext{
${ }^{8}$ In this question, subjects are told that they are competing in a five-mile race and, in the final mile of the run, have passed the person in $96^{\text {th }}$ position ( $2^{\text {nd }}$ position in the original). "In which position did you finish?" See the Appendix for this and the other 3 questions.
} 
To convey our genuine intent to carry out the payments as described, we reassure subjects in the first page of participants' instructions. Specifically, we write, "Please be assured that everything stated in the instructions is accurate and true, including the method to determine your payment. Deception is strictly forbidden in economic research.” In the event that they do not receive their promised payment on time, we invited subjects to contact the one of the researchers (Ruffle) by email or telephone. Andreoni and Sprenger (2012) employ a similar procedure to enhance the experimenters' trustworthiness in the eyes of their subjects.

\section{Results}

\subsection{Summary Statistics}

One thousand one hundred four (1104) American respondents participated in our study. Seven hundred eighty-one (781) reported having no tattoos (abbreviated henceforth as "non-tattooed”), while 255 indicated having one or more tattoos, all of which can be easily hidden with clothing (e.g., a long-sleeve shirt or long pants) (abbreviated as "hidden tattooed” or simply "hiddens”). The remaining 68 subjects reported having at least one visible tattoo (e.g., face, neck, hand) (abbreviated as "visibly tattooed” or “visibles”). This amounts to 30\% of our sample being tattooed. If we restrict attention to subjects aged 26-40 years old for comparability with the (40\%) statistic cited in our opening paragraph, 34\% of our sample is tattooed.

Nearly twice as many women are tattooed (39\%) as men (21\%). ${ }^{9}$ This also holds true for the rates of both hidden (30.2\% vs. 16.7\%) and visible tattoos (8.5\% vs. 4.1\%). Moreover, the visibly tattooed report 9.6 tattoos on average (median of 3.5 tattoos), four times more than the mean number of tattoos (2.4) for those with only hidden tattoos (median of 1 tattoo).

There is some modest regional variation with 33.5\% tattooed in Midwestern states, 29.1\% in Northeastern states and about 27.5\% in Southern and Western states. Summary statistics appear in the left column under each tattoo status of Table 2, Panel A for all of the other sociodemographic controls included in our regression analyses (to be discussed in section 3.2). Although the age, income and employment status distributions of the non-tattooed, hiddens and visibles are not statistically different from one another at conventional significance levels, the

\footnotetext{
${ }^{9}$ The higher incidence of tattoos among women finds support in a poll conducted by the U.S. TV network behind the show "Best Ink" and Lightspeed Research according to which women are about 50\% more likely than men to have one or more tattoos (Sinha-Roy 2012).
} 
visibles report significantly lower educational attainment. ${ }^{10}$ To our surprise, the visibly tattooed report higher levels of religiosity than the non-tattooed and hidden tattooed on all three measures collected. In particular, the visibly tattooed report significantly stronger beliefs in God than the non-tattooed and hidden tattooed (Wilcoxon p-values .05 and .02, respectively) and stronger religious beliefs than the hidden tattooed $(p=.08) .{ }^{11}$ Finally and consistent with evidence that the tattooed are more likely to engage in a number of risky behaviors (Deschesnes et al. 2006), we find that the visibly tattooed report a significantly higher willingness than the non-tattooed to take risks (Wilcoxon p-value .02).

With some notable differences, the characteristics of our sample broadly reflect those of the U.S. population. Specifically, the geographic dispersion of our subjects $(17.8 \%$ Northeast vs. actual 17.4\%; 23.8\% Midwest vs. 21.0\%; 41.1\% South vs. 37.9\%; 17.3\% West vs. 23.7\%) and the percentage of whites in our sample (77.4\% vs. $76.9 \%)$ mirrors closely those of the U.S. population more generally, according to 2016 U.S. census data. The most obvious dimension along which our sample differs from the broader population is its exclusion of the $13 \%$ of Americans who do not use the internet. In addition, women, blacks, Hispanics and especially seniors are underrepresented in our sample, whereas men, Asians and 25-44 year-olds are slightly over-represented. With $99.6 \%$ of our sample having completed high school (vs. 86.7\% in the U.S. population) and $55.5 \%$ with a college degree (vs. $29.8 \%$ in U.S. population), our sample is considerably more educated the U.S. population as a whole. ${ }^{12}$ Finally, our sample is considerably less Christian (37.3\%), with much higher percentages claiming to be atheist (20.1\%), agnostic (19.0\%) or no

\footnotetext{
${ }^{10}$ French et al. (2016) find that the tattooed report lower earnings, higher unemployment and lower educational attainment than the non-tattooed in national longitudinal datasets from the U.S. and Australia. See Tables 1 and 4 in their paper. Based on a representative Dutch panel, Dillingh et al. (2016) show that the (visibly) tattooed, have lower educational outcomes and a higher chance of being unemployed, but not significantly lower earnings.

${ }^{11}$ This is particularly striking when contrasted with the views of traditional Judaism and Islam which forbid tattoos and many Christians who take exception to tattoos citing Leviticus 19:28: "Do not cut your bodies for the dead or put tattoo marks on yourselves. I am the Lord.” Moreover, Degelman and Price (2002) find that the tattooed are perceived as less religious. Koch et al. (2004) show that, among students at a university in the southwestern U.S., religious faith has a weak negative correlation with having a tattoo, whereas church attendance or frequency of prayer did not predict tattoo incidence or the attitudes toward tattoos. Dillingh et al. (2016) find that the tattooed are, on the one hand, less likely to believe in God and pray less often, but, on the other hand, they are just as likely to believe in the afterlife and possess stronger beliefs in reincarnation and karma. None of these studies distinguishes between hidden and visible tattoos, although the latter study has the data to do so. The two former studies were conducted more than a decade ago when tattoos were considerably less mainstream.

${ }^{12}$ Sources: The comparative U.S. population data for age, sex, geographic distribution, ethnicity and education comes from the U.S. Census Bureau, 2016 Annual Social and Economic Supplement. For a summary, see, for example, https://www.census.gov/quickfacts/fact/table/US/PST045216. Detailed data on the U.S. age distribution can be found at https://www.census.gov/content/dam/Census/library/publications/2011/dec/c2010br-03.pdf. The internet usage data from Pew Research Center's 2016 annual survey and are summarized in Anderson and Perrin (2016).
} 
religion (9.2\%) than the findings of the American Religious Identification Survey (2008), which reports 76.0\% Christian and only 15.0\% atheist, agnostic or no religion (see Kosmin et al. 2009).

The first three rows of Table 2, Panel B display the distribution of subjects' choices in the time-preferences task by tattoo status according to whether they switch to Option B and remain there through Pair 10, never switch to Option B or switch to Option B and irrationally back to Option A at least once. While similar percentages of non-tattooed and hidden tattooed (about 83\%) switch once to Option B, a noticeably lower percentage of the visibly tattooed (72\%) display this behavior. At the same time, only tiny percentages (1.8\% and $1.2 \%$, respectively) of the nontattooed and hidden tattooed switch multiple times compared to a full one in ten (or 10.3\%) of the visibly tattooed who do so. The non-parametric, rank-order Kruskal-Wallis test reveals that these distributions of outcomes by tattoo status differ significantly from one another $\left(\chi^{2}(2)=2.92, p=\right.$ $.04)$. This initial evidence suggests that the visibly tattooed exhibit less rational decision-making on average at this task than the hidden and non-tattooed.

The regressions on the pair at which subjects switch from Option A to Option B (reported in the next subsection) necessarily drops those subjects who switch multiple times. The right column under each tattoo status in Table 2, Panel A reports the summary statistics for the sociodemographic variables on the remaining sample. Because fewer than two percent of the nontattooed and hidden tattooed switch more than once, these values are virtually unchanged from those reported on the full sample, whereas a couple of the values for the visibly tattooed change more substantially (e.g., church attendance is lower and the proportion of females even higher).

The fourth row of Table 2, Panel B reports the mean switching pair by tattoo status among subjects who did not switch multiple times, where those who chose option A through all 10 pairs are coded as pair 11 . The non-tattooed switch at pair 6.56 on average, about half a pair earlier than the hidden tattooed (7.02) and nearly two full pairs before the visibly tattooed (8.38). Interpolating the dollar amounts between pairs, the non-tattooed require about $\$ 1.55$ on average to switch to Option B, while the visibles demand over \$2, about one-third more. Figure 1 displays the full distributions of switching pairs by tattoo status. Most striking is the $18 \%$ of non-tattooed subjects who already switch at Pair 2, compared to $13 \%$ of hidden tattooed subjects and a mere $1.6 \%$ of visibly tattooed subjects. At the other end of the distribution, $61 \%$ of the visibly tattooed either wait until Pairs 9 or 10 to switch or never switch at all (coded as Pair 11). By contrast, only 37\% of the non-tattooed wait so long before switching to Option B. Pairwise Wilcoxon rank-sum tests 
strongly rejects the equality of the distributions of switching pairs for the non-tattooed and visibly tattooed samples and for the hidden and visibly tattooed samples ( $p<.01$ in both cases) and weakly rejects their equality for the non-tattooed and hidden samples $(p=.06)$.

Figure 2 displays the robustness of our main finding that tattooed subjects are more shortsighted for different age cohorts. We divide the observations in the 26-40 age cohort into two roughly equally sized groups, ages 26-31 $(N=330)$ and ages 32-40 $(N=333)$. The remaining age cohorts are ages 18-25 $(N=171)$ and above $40(N=270)$. The horizontal dashed lines reveal the fraction of subjects that are tattooed in each age cohort. The highest incidence of tattoos (38.1\%) is observed among the 32- to 40-year-olds. Above 40, the incidence of tattoos drops 19 percentage points to $19.3 \%$. The height of each observation (dot) shows the fraction of tattooed subjects among the total number of subjects that switched from Option A to Option B at the indicated pair. What stands out in all four age cohorts is the increasing fraction of tattooed subjects as the switching pair increases. In particular, the tattooed tend to be under-represented (relative to their proportion in each age cohort) among those subjects who are more future-oriented and switch early (pairs 1-5). At the same time, the tattooed tend to be over-represented in each age cohort among those who are heavily present-oriented and switch late (pairs 9-11).

Table 3 provides further evidence of the short-sightedness of the tattooed in the financial, health and social domains. The entries indicate the mean response (standard deviation) for each domain-specific question where all of the responses are coded such that larger values correspond to increased short-sightedness. For all behaviors in all domains, both the hidden and visibly tattooed display more short-sightedness than the non-tattooed. ${ }^{13}$ The bold entries are those that are significantly different from the others in the same row according to pairwise Wilcoxon rank-sum tests. Thus, for example, the non-tattooed report saving more for retirement, make fewer late credit-card payments and better manage their debt and finances than the hidden and visibly tattooed, while these latter two groups are not significantly different from one another along any of these financial measures. The non-tattooed also report drinking and smoking significantly less and are significantly less likely to post personal or controversial statements online than the hidden and visibly tattooed; those with hidden tattoos also report significantly less smoking and both

\footnotetext{
13 The single exception is that the visibly tattooed exercise more regularly on average than the non-tattooed; although the difference is not statistically significant $(p=.21)$.
} 
online behaviors than do the visibly tattooed. Finally, the non-tattooed and hidden tattooed report significantly less willingness to sacrifice their future for a good time now than the visibly tattooed.

The percentages of subjects that correctly answered each of the four CRT questions appear in the left-most columns in Table 4 according to tattoo status. The non-tattooed show higher rates of success at all four questions than the hidden tattooed who do better than the visibly tattooed at the first three questions and match their success rate at the fourth question. Quite starkly, the modal number of correctly answered questions is all four for the non-tattooed (30.2\% of subjects) versus zero correct answers for the hidden (26.7\%) and zero for the visibly tattooed (38.2\%).

While incorrect answers on the CRT are often thought to reflect intuitive or impulsive thinking, it is also possible to give an otherwise incorrect, but unintuitive answer. The middle and right-most columns in Table 4 distinguish between subjects who gave the intuitive, incorrect answer ("Intuitive”) and those who gave some other unintuitive answer ("Wrong”). For CRT questions 1, 2 and 4, compared to the non-tattooed, the hidden tattooed have a much higher rate of intuitive, incorrect answers along with a similar rate of other unintuitive answers. One interpretation of this finding is that if the hiddens had not been so impulsive and instead spent more time contemplating these three CRT questions before responding, their success rate would have matched those of the non-tattooed. By contrast, the visibles have higher percentages of both types of incorrect answers (intuitive and unintuitive) than the non-tattooed for all four CRT questions. This suggests that even if the visibles had taken more time before submitting their answers, they still would have underperformed the non-tattooed.

Taken together, we have seen compelling evidence across varying decision types and behavioral domains that those with tattoos, especially visible ones, are more short-sighted and impulsive than the non-tattooed. In what follows, we will examine the robustness of these findings when controlling for a host of other explanatory variables and determine whether certain motives for getting a tattoo, the time spent contemplating one's first tattoo and the time elapsed since one's most recent tattoo and other information gathered about individuals' tattoos attenuate these results.

\subsection{Tattoos and Time Preferences}

Regression (1) in Table 5 reports the results from a simple OLS regression on the pair at which subject $i$ switched from Option A to Option B (multiple switchers are excluded, those who never 
switched to Option B are coded as 11). ${ }^{14}$ Indicator variables for hidden and visible tattoos and a constant (no tattoo) are the only regressors. Heteroskedasticity-robust standard errors appear in parentheses. Both the estimated coefficients of 0.46 and 1.82 on the "Hidden" and "Visible" indicators, respectively, are significantly different from zero $(p=.04$ and $p<.01)$, indicating that the hiddens and visibles switch about half a pair and nearly two pairs later, respectively than the non-tattooed. The difference between Hidden and Visible of 1.36 pairs is also highly significant $(p<.01)$.

We saw that the visibly tattooed have four times as many tattoos on average as the hidden tattooed. Perhaps the Hidden-Visible distinction in (1) serves as a proxy for the number of tattoos. After controlling for subject $i$ 's number of tattoos in regression (2), the estimates on Hidden and Visible remain unchanged, while the number of tattoos is not significantly different from zero. Allowing for a non-linear relationship between the number of tattoos and the switching pair in the time-preferences task by including a squared term for the former measure increases slightly both the Hidden and Visible estimates in (3), while neither the number of tattoos nor the squared term offers any explanatory power. ${ }^{15}$

The subject's stated willingness to take risks is added as a regressor to regression (4). An additional increment in the subject's preparedness to take risks corresponds to switching to Option B 0.84 pairs later $(p=.03)$. In words, risk-taking and short-sightedness are positively correlated. This result is notable when contrasted with a number of papers that estimate both subjects' time and risk preferences and find that increased risk aversion is associated with lower rates of discounting the future (e.g., Anderhub et al. 2001; Eckel et al. 2005; Andersen et al. 2008). To reconcile the apparent discrepancy between this result and ours note that these papers elicit subjects' risk preferences by having them choose how much of their endowment to investment in a risky financial asset or choose between pairs of risky and relatively safe lotteries. By contrast, our risk measure asks whether the subject is "generally a person who is fully prepared to take

\footnotetext{
${ }^{14}$ For the $15.4 \%$ of the subjects who never switch to Option B, their decision to switch is censored and coding this decision as "11" possibly underestimates their reluctance to switch. The significance and non-significance of all of our variables of interest remain unchanged if we exclude these subjects from the analysis or replace the OLS regressions with double-sided Tobit regressions with left censoring at 1 and right censoring at 11 .

${ }^{15}$ All of the estimates and their (non-)significance in these and all other regressions remain qualitatively the same if we exclude the three subjects in our sample with more than 34 tattoos, which is two standard deviations above the mean number of tattoos among the tattooed.
} 
risks”. Subjects likely have in mind risks that pose a danger to their physical well-being when responding to this question, rather than risk concerning financial decisions.

Regression (5) also includes a host of socio-demographic controls: the subject's age, education, sex, income, employment status, census region, frequency of church attendance and strength of religious beliefs. Older and more educated subjects switch to Option B sooner (i.e., are more future-oriented), while stronger religious beliefs predict later switching (i.e., more presentoriented). The coefficient of 1.72 on Visible remains highly significant with the inclusion of these controls, whereas the Hidden estimate falls to 0.33 and is no longer significantly different from zero $(p=.18) .{ }^{16}$

\subsection{Tattoos and Impulsivity}

Is impulsivity the source of tattooed individuals' observed short-sighted preferences in our incentivized experiment? To address this possibility, we include indicator variables for the subject's number of correctly answered CRT questions in regression (6). The narrowly varying estimates from -0.55 to -0.66 ( $p$-values from 0.04 to 0.09 ) on one, two and three correctly answered questions imply that subjects who correctly solved one, two or three questions switched to Option B about half a pair earlier than the omitted category of subjects who got all four questions wrong. The absolute magnitude of the coefficient on all four correct answers increases to $-1.34(p<.01)$, indicating that these subjects switched 1.34 pairs before those who answered zero correctly. Moreover, these former subjects switched significantly earlier than those who answered one, two or three correctly ( $p \leq .01$ or less for all pairwise t-tests). The inclusion of these CRT dummies reduces only modestly the magnitudes of the Hidden and Visible coefficients. The estimate of 0.25 on Hidden continues to be nonsignificant ( $p=.32$ ), while Visible (1.57) remains significantly different from zero and from the Hidden estimate $\left(p<.01\right.$ in both cases). ${ }^{17}$ Hence, even after

\footnotetext{
${ }^{16}$ Further regression analyses in which we include different subsets of the socio-demographic controls lead to the conclusion that no single regressor is responsible for the lack of significance of the Hidden variable. In fact, the three regressors age, education and income are all necessary to render the estimate on Hidden non-significant. If we exclude any one of these three variables, the significance of the Hidden estimate is restored. None of the other variables related to religiosity, region or sex detract from the significance of Hidden.

${ }^{17}$ We asked subjects at the end of the survey whether they had previously seen the exact or some version of each of the CRT questions. See the Appendix for these questions and available responses. The inclusion of indicator variables for the different responses for each CRT question are mostly non-significant and leave the Hidden and Visible estimates virtually unchanged.
} 
accounting for impulsivity, the visibly tattooed are significantly more short-sighted than the hidden tattooed and the non-tattooed.

\subsection{Motives for Getting Tattooed}

All reasons for getting a tattoo may not be equally short-sighted. Some may be better thought out than others. For example, a tattoo to memorialize a loved one or to remember a certain time period in life may be more meaningful, carefully considered and forward-looking than a tattoo decided upon spontaneously, without reason or because one's friends are tattooed. We asked tattooed subjects to provide the explanations that describe why they got tattooed and allowed them to choose as many reasons as applicable for their hidden tattoos and separately their visible ones. We provided ten reasons and, in case we missed any, added “Other" along with a textbox. Table 6 displays the distributions of reasons for getting a tattoo separately for individuals' hidden and visible tattoos. "Expression of individuality" and "Like the way the tattoo looks" were the most commonly cited reasons for hidden tattoos. For visible tattoos, these two reasons were cited as the most and second-most common motives, respectively, along with "statement of personal identity”, which tied for second. Other reasons provided by at least $10 \%$ of the tattooed respondents were (in descending order) “to remember a particular time in my life”, "to memorialize a loved one”, “as a snap or impulsive decision” and “to create a certain image of me”.

Regression (7) in Table 5 includes indicators for all 11 reasons to determine whether some might mitigate the hereto observed short-sightedness associated with tattoos. None do. While the signs on these reasons vary from positive to negative, none is significantly different from zero.

Several of the ten reasons share common traits. For example, "expression of individuality”, “statement of personal identity”, and “to create a certain image of me” are all expressions of one's identity. Also, "to remember a particular time in my life" and "to memorialize a loved one” both invoke tattoos to remember something. Finally, getting a tattoo because "most friends are tattooed" or because one "belong[s] to a group who are tattooed" are both social reasons. In an effort to increase the statistical power of these motives, we combined the first three identity-related reasons into a single motive, and similarly for the two memory-based and the two socially motivated 
reasons. ${ }^{18}$ Still none of these combined motives nor any of the individual motives is a significant predictor of time preference (results not shown, but available upon request).

\subsection{Tattoos and Domain-Specific Short-Sightedness}

We already saw evidence in section 3.1 that the tattooed engage in more short-sighted behaviors in the financial, health and social domains. We will now employ seemingly unrelated regressions (SUR) to determine whether they exhibit more short-sightedness in one domain or another. SUR estimation offers efficiency gains over separate OLS equations by accounting for the crossequation correlation in the error terms (Zellner 1962).

To begin, we calculate each subject's standardized response to each domain-specific question by subtracting the question mean from the subject's response and dividing by the standard deviation. Next, we compute each subject's average domain-specific standardized response. Then, using SUR, we regress each subject's domain-specific average on indicators for Hidden and Visible, as well as other domain-specific controls. More precisely,

$$
\bar{y}_{l}=\alpha_{0}+\alpha_{1} \cdot \text { Hidden }+\alpha_{2} \cdot \text { Visible }+\alpha_{3} \cdot X_{i}+\epsilon_{i}
$$

where $\bar{y}_{l}$ is subject $i$ 's domain-specific standardized mean response and $X_{i}$ is a vector of domainspecific controls, such as income for the financial domain, whether the subject is overweight for the health domain, and time spent on social media for the social domain. The random error term is $\epsilon_{i}$

The estimates from the SUR model appear in Table 7. By rejecting the independence of the cross-equation error terms, the Breusch-Pagan test $\left(\chi^{2}(2)=78.3, p<.01\right)$ validates the choice of the SUR model. Across all three domains, we see that Hidden is significantly different from zero and positive, implying the hiddens are more short-sighted than the non-tattooed in all three domains. The Hidden coefficients vary within the narrow band between .126 and .178. In fact, none of these estimates is significantly different from one another ( $p$-values from Wald tests range from .36 to .86). The Visible estimates are also all positive; however, the estimate of .121 in the financial domain does not differ significantly from zero $(p=.16)$, while the estimates of .323 and .339 in the health and social regressions are highly significant. Not only are the visibly tattooed more short-sighted than the non-tattooed in the health and social domains, Wald tests of

\footnotetext{
${ }^{18}$ Similarly, Carmen et al. (2012) suggest that the motives for getting a tattoo "tend to fall into three categories: (a) a symbol of an important past event, love or friendship, (b) group membership, and/or (c) a marker of individuality.”
} 
coefficients reveal that they are also more short-sighted than the hidden tattooed in these domains $(p<.05)$. These findings serve to validate our time discounting measure and our interpretation of the results from that measure that the visibly tattooed are more short-sighted than the hidden tattooed who are more short-sighted than the non-tattooed. What is more, the finding that the visibly tattooed are even more short-sighted in the health and social domains than in the financial domain suggests that the results from our incentivized financial measure of short-sightedness may understate the extent to which the visibly tattooed are more broadly short-sighted. ${ }^{19}$

\section{Robustness Checks}

\subsection{Gender}

Next, we explore whether the observed present orientation and impulsiveness of the tattooed, especially the visibly tattooed, continues to hold on different subsamples. To begin, does the relationship apply equally to both sexes? We've already noted that women are about twice as likely as men to have hidden and visible tattoos. Moreover, relative to the other sex, men tend to prefer tattoos on their biceps and shoulders, whereas women prefer tattoos on their upper and lower back and on their calves, ankles and feet. ${ }^{20}$ Regressions (8) and (9) in Table 8 report estimates from separate regressions on men and women, respectively. Both regressions reveal that visibly tattooed men and women switch to Option B significantly later, 1.92 and 1.43 pairs, respectively, than their non-tattooed, same-sex counterparts $(p<.01$ in both cases). Thus, a visible tattoo is unambiguously associated with more myopic time preferences for both sexes.

The findings for the hidden tattooed are not so absolute. Men with only hidden tattoos switch 0.67 pairs later than non-tattooed men $(p=.07)$, whereas the miniscule estimate of -0.02 ( $p=.94$ ) on the Hidden variable for women in (9) implies that there is no difference in the elicited time preferences between women with only hidden tattoos and those without tattoos.

As for impulsivity, Table 9 provides the mean CRT scores by sex and by tattoo status. Among men, the non-tattooed answer significantly more questions correctly on average (2.54) than the hidden tattooed (2.09) $(p<.01$ from Wilcoxon nonparametric test) who answer more questions correctly than visibly tattooed men (1.50) ( $p=.07)$. Among women, the visibly tattooed

\footnotetext{
19 This interpretation is reinforced by the finding that the subject's choice of switching pair in the incentivized experiment is more highly correlated with the subject's standardized mean response from the financial domain than from the health or social domains.

${ }^{20}$ The full distribution of body parts on which our sample of men and women get tattooed is available upon request.
} 
answer significantly fewer questions correctly (1.36) than the non-tattooed (1.89) $(p=.02)$; however, there is no significant difference in performance between the hidden tattooed (1.72) and the non-tattooed $(p=.25) .^{21}$

Overall, the picture that emerges from these findings is that both visibly and hidden tattooed men are more short-sighted and impulsive than their non-tattooed counterparts; yet, while visibly tattooed women are more short-sighted and impulsive than non-tattooed women, women with only hidden tattoos are not significantly different from non-tattooed women along either of these measures.

\subsection{Tattooed only}

In the tattoo portion of the survey, we directed several questions to the tattooed about their decision to get a tattoo. Their responses allow us to explore further the robustness of the observed behavioral differences between the hidden and visibly tattooed. To begin, we asked all tattooed subjects how long they contemplated their first tattoo before they went ahead and got it done. ${ }^{22}$ Table 10 presents the distribution of responses separately for the hidden and visibly tattooed. What stands out about these distributions is that for the four shortest lengths of contemplation (i.e., "spontaneous”, “a day or two", "several weeks” and “a week or more”), the percentage of visibles exceeds that of hiddens. By contrast, for the two longest timespans (i.e., "at least a month" and "more than a year"), the ordering reverses with the percentage of hiddens surpassing that of the visibles. The clear conclusion is that the visibles spent significantly less time contemplating their first tattoo than the hiddens (Wilcoxon test $z=2.03, p=.04$ ) - yet further evidence of the impulsivity of the visibly tattooed.

Do subjects who contemplated their tattoo longer before getting it done display more future-oriented time preferences in our experiment relative to those whose decision to get a tattoo was spontaneous? The results from regression (10) in Table 11 provide only limited support for this hypothesis. It includes indicator variables for five of the six timespans listed in the question (see the Appendix for the question), with “I didn't give it much thought, it was done

\footnotetext{
${ }^{21}$ Elsewhere males have also been observed to perform better than females on the CRT test (see Brañas-Garza et al. 2015 for a recent survey as well as additional evidence on gender differences in CRT performance).

${ }^{22}$ The reason for asking about subjects' first tattoo ought to be clear. Having gone through the process, subjects with multiple tattoos presumably devote less time to contemplating subsequent tattoos. Since the visibly tattooed have on average more tattoos, asking subjects about, say, their most recent tattoo would bias the results toward the visibles contemplating less their tattoo than the hiddens.
} 
spontaneously" as the omitted response. While all of the timespan estimates are negative with respect to the omitted spontaneous decision, only the coefficient of -1.23 on "several days" differs significantly from zero. This estimate implies that subjects who contemplated their tattoo several days before following through switch to Option B 1.23 pairs earlier than those whose first tattoo was done spontaneously.

With the inclusion of these timespan indicators, the visibly tattooed remain significantly more present-oriented than the hidden tattooed, switching to Option B about 1.5 pairs later than the hiddens.

Another robustness check centers on when the tattooed got their most recent tattoo. There exist two opposing hypotheses about how long ago subjects received their most recent tattoo and their time preferences. On the one hand, someone who got tattooed more than 20 years ago may be very short-sighted since they made their choice despite tattoos being heavily stigmatized at the time.

On the other hand, the more time that has elapsed since the subject's most recent tattoo, the more time the subject has had to change and perhaps develop more patience. Hong et al. (2016) present an alternative explanation. The authors model a decision-maker with present-biased preferences and a limited memory who learns his type in period one. Recognizing that he may forget his type in the next period, the high-ability type willingly incurs a sunk cost to signal his type to his future self, thereby encouraging the future self to undertake the disciplined course of action of investment in a project, despite his present-biased preferences. They offer tattooing as an example of a sunk cost that serves to remind future selves to be more disciplined.

Our dataset provides several strands of evidence that address the self-signaling hypothesis. To begin, among the respondents who did not select any of the ten reasons provided for getting a tattoo, but instead chose "Other", one subject cited "To mark a significant change of life" and another wrote "Reminder of what is important". Both explanations can be interpreted as reminders of self-management. Also, subjects who are the most impatient and impulsive are most in need of self-management and thus might be expected to be the most likely candidates to get a tattoo in the coming year. This is consistent with our findings from section 3.3. Finally, to the extent that a tattoo is a successful self-discipline strategy, we would expect that, among the tattooed, the longer ago tattooed individuals received their most recent tattoo, the more they have succeeded in 
reducing their impatience. Thus, the time elapsed since the most recent tattoo is predicted to mitigate the degree of impatience among the tattooed.

We asked tattooed subjects when they received their most recent tattoo. The Appendix offers the exact question and set of responses. Regression (11) in Table 12 includes the timeframe in which the subject received his last tattoo. The response "within the past year" is omitted. The estimates on these variables are small and vary in sign from positive to negative. None is significantly different from zero. ${ }^{23}$ Regression (12) combines all of the most-recent-tattoo timeframes of less than 20 years ago into a single category to contrast it with most recent tattoos obtained more than 20 years ago when tattoos were still unconventional. The estimate of -0.21 on this latter variable remains nonsignificant $(p=.79)$. With highly significant estimates on the Visible indicator of 1.29 in (11) and 1.41 in (12), both regressions reveal that the visibly tattooed continue to be more short-sighted than the hidden tattooed. In short, even though tattoos have gained mainstream acceptance, we present evidence that the more recently tattooed are every bit as short-sighted as those whose last tattoo was long ago when tattoos were stigmatized.

Finally, the age at which one chose to first get tattooed (abbreviated as "tattoo age") may predict one's time preferences. Specifically, the younger the tattoo age, the more short-sighted and impulsive one is hypothesized to be. At the same time, the passage of time may mitigate the characteristics attributed to youth, especially if one got tattooed a long time ago. Although we did not ask subjects the age at which they got their first tattoo, for those 148 subjects in our sample with only one tattoo, we can compute the age of their first tattoo by subtracting the time that has elapsed since their last (and only) tattoo from their current age. ${ }^{24}$ When we regress an indicator variable for the visibly tattooed, the subject's current age and tattoo age on the subject's switching pair, the visibles switch 1.85 pairs later than the hiddens $(p<.01)$ while the coefficient of 0.03 on tattoo age is not significant ( $p=.53$ ). The estimate on the visible indicator drops slightly to 1.48 $(p=.02)$ when our risk measure and full set of socio-demographic controls are included, but the

\footnotetext{
${ }^{23}$ Importantly, age is among the socio-demographic controls included in this and all other regressions. Without age, time elapsed since the most recent tattoo and age are confounded. Even without age, none of the estimates on the timeframe indicators differs significantly from zero. In a specification not shown, we also included interaction terms between each of the timeframe indicators and a dichotomous age variable equal to one for subjects older than 40 years of age; none of the timeframe indicators or the interaction terms is significantly different from zero.

${ }^{24}$ For those who were tattooed "over 20 years ago", we set the number of years since their tattoo at 21 . Thus, the age of their first tattoo is less accurately determined. The vast majority of the 21 subjects who were tattooed over 20 years ago are in their late 30s or 40s, implying they were tattooed in their late teens or twenties.
} 
tattoo age coefficient of .03 remains unchanged $(p=.47) .{ }^{25}$ The implication is that the age at which one first got tattooed does not predict one's current time preferences.

\section{Explanations}

\subsection{Causality}

Are more short-sighted individuals more likely to get a tattoo, or does getting a tattoo lead to shortsightedness? More explicitly, it could be that getting a tattoo is an expression of one's shortsightedness, just as, more than a decade ago, Braithwaite et al. (2001) and Descheneses et al. (2006) found that heavy drinking and the use of illicit drugs were behaviors more commonly observed among the tattooed than the non-tattooed. On the other hand, it could be that getting tattooed leads one to become more short-sighted. A possible reasoning goes as follows: after getting tattooed one finds it difficult to obtain one's preferred job - perhaps due to discrimination against (visible) tattoos. As a result, one accepts a lesser paying job. Consequently, one is often engaged in the short-term thinking required to make ends meet with scarce resources to think about the future or saving for retirement. ${ }^{26}$ This short-term thinking expresses itself in our timepreferences experiment.

This reasoning for tattoos leading to short-sightedness is predicated on the tattooed earning less than the non-tattooed, an assumption that finds no support in our data. Table 13 reports OLS regressions on subjects' reported net monthly income. The estimates reveal that the earnings of the hidden and visibly tattooed are not significantly different from the non-tattooed, neither in the absence of any control variables (13) nor in the presence of the entire suite of socio-demographic and risk controls (14). ${ }^{27}$ Regression (14) also shows that the pair at which subject $i$ switched to Option B in the incentivized experiment is not a significant predictor of income $(p=.98)$.

\footnotetext{
${ }^{25}$ These regressions are not displayed, but are available upon request. We also regressed tattoo age on the subject's number of correctly answered CRT questions. The estimates of -0.006 and -0.010 without and with the suite of sociodemographic and risk controls, respectively, are not significantly different from zero ( $p=.75$ and $p=.71)$.

${ }^{26}$ Along similar lines, Shah et al. (2012) show that randomly endowing individuals with budgets of varying amounts leads those with limited resources to excessive borrowing.

${ }^{27}$ Consistent with our findings, French et al. (2016) and Dillingh et al. (2016) do not find that the tattooed earn significantly less than the non-tattooed after controlling for educational attainment and other socio-demographic characteristics. Unlike these authors, we do not find that the tattooed (hiddens or visibles) are less likely to be employed full-time nor are they more likely to be unemployed than the non-tattooed.
} 
Even more direct evidence in support of the hypothesis that short-sightedness leads to tattoos rather than the other way around comes from subjects' responses to a question about their intent to get a tattoo within the coming year.

The distinction we've drawn thus far between the tattooed who chose to get one or more tattoos sometime in the past and the non-tattooed who have chosen not to get a tattoo right up to the present moment compares two sets of temporally incongruent decisions. Some non-tattooed individuals may be seriously contemplating getting tattooed, whereas some tattooed may be very different people today compared to when they got tattooed in the, perhaps distant, past. Tattoo removal could equip us with a more current picture of tattooed individuals' attitudes toward tattoos; however, only seven subjects in our sample have ever had a tattoo removed.

To compare the tattooed and non-tattooed individuals' current attitudes toward tattoos, we asked all subjects how likely they are to get a(nother) tattoo within the next year. Seven possible answers were provided ranging from "no chance whatsoever" and "highly unlikely" to "probably will” and "almost definitely will”. Figure 3 displays the mean switching pair (plus or minus one standard deviation) for each of the possible seven responses. The graph displays an upward trend; namely, the more likely respondents are to get a tattoo within the coming year, the later the pair at which they switch to Option B (i.e., the more short-sighted they are). For example, regression (15) in Table 14 shows that subjects who answered that they "probably will” or "almost definitely will" get a tattoo within a year switch 1.15 pairs later on average than those who were less certain, controlling for all of the socio-demographic characteristics.

Regression (16) reintroduces the Hidden and Visible indicator variables. The coefficient on the combined response category of "probably will” and "almost definitely will” get a tattoo remains highly significant and reveals that these subjects switch about one pair later than everyone else. The inclusion of this variable renders the Hidden coefficient of 0.13 nonsignificant, while the Visible coefficient of 1.34 remains highly significant.

The decision to get a tattoo may follow different stochastic processes for the tattooed and non-tattooed. In particular, an individual without a tattoo may perceive the costs of getting one to be substantially higher than someone who has already been through the experience and lived with the tattoo. To allow for this, Figure 4 plots the time preferences (i.e., mean switching pair) as a function of the likelihood of a getting a tattoo within the next year separately for the tattooed and non-tattooed. For both types, but especially the non-tattooed, the switch to Option B occurs later 
the greater one's intention to get tattooed in the year to come. Regression (17) interacts the combined response category of "probably will” and "almost definitely will” (henceforth referred to as "highly likely") separately with the non-tattooed and the tattooed. The estimates reveal that the highly likely non-tattooed wait an additional two pairs before switching to Option B than the non-tattooed who are less likely to get tattooed. Put simply, the mere intent to get a tattoo is associated with increased short-sightedness. Meanwhile, the already tattooed individuals who are highly likely to get another tattoo in the next year wait 0.62 pairs more before switching to Option $\mathrm{B}$ than the tattooed who are less likely to get another tattoo $(p=.09)$. Moreover, the time preferences of the tattooed and non-tattooed who are highly likely to get (another) tattoo within the next year are not significantly different from one another $(p=.20)$. In words, regardless of current tattoo status, those intending to get a tattoo within the next year are more short-sighted, switching a full pair later than those who are less likely to get a tattoo. Combining this result with the most basic finding from the Results section, we conclude that, whether past or planned, tattoos are associated with more myopic time preferences.

Our finding that the mere intention to get a tattoo predicts short-sightedness and that this holds at least as strongly among the non-tattooed as the tattooed contradicts the "tattoos cause short-sightedness" direction of causality. Instead this result is consistent with the notion that individuals who possess the trait of short-sightedness are more likely to get tattooed.

\subsection{Do they not care or are they unaware?}

Do the tattooed make the decision to get tattooed knowing full well that they may face discrimination in the labor market? Or do they underestimate the extent to which tattoos may be negatively viewed, perhaps because they believe tattoos are more normative in society than is actually the case?

We collected several measures that address these alternative hypotheses. Table 15 reports the mean (standard deviation) for each measure, by tattoo status. To begin, tattooed individuals who are aware that others may view their tattoos negatively, but nonetheless proceed to get tattooed may be said to place less importance on what others think of them. We asked all participants in our study, "How important is it to you what others think of you?" on a 1-7 scale where 1 corresponds to "not important at all” and 7 equates to "very important." Contrary to the not-caring hypothesis, the visibly tattooed report placing the most importance on what others think of them 
(mean $=4.13)$ compared to means of 3.78 for hiddens and 4.00 for non-tattooed; although the Kruskal-Wallis test cannot quite reject at conventional significance levels that these three sample distributions are drawn from the same population distribution $(p=.11)$.

Also, if the tattooed don't care what others think of them, we would not expect the motivations for getting a tattoo involving self-expression, statements of personal identity and image creation to figure prominently. And yet, they are the top two and seventh most commonly cited motives for visible tattoos, and the first, third and seventh most cited for hidden tattoos. ${ }^{28}$

At the same time, we have several strands of evidence in support of the tattooeds' overestimation of the normativeness of tattoos in society and underestimation of their potential handicap in the workplace. We asked subjects to estimate the percentages of their friends and the American population with one or more tattoos. The visibly tattooed have significantly higher percentages of tattooed friends (64\% on average) than the hidden tattooed (55\% on average) who have significantly higher percentages of tattooed friends than the non-tattooed (29\% on average) $\left(p<.02\right.$ for all three pairwise Wilcoxon tests). ${ }^{29}$

What is more, the visibles and hiddens estimate that $53 \%$ and $49 \%$, respectively, of Americans have at least one tattoo. Both of these estimates substantially exceed the percentage tattooed, even among the age group with the highest tattoo rate. By comparison, the non-tattooeds’ average estimate is a more realistic 36\%. This evidence indicates that the tattooed, the visibles in particular, have both a circle of friends and a view of American society in which the tattooed are over-represented.

If we categorize subjects according to their intentions to get a tattoo in the coming year, once again, the non-tattooed who are likely to get a tattoo respond much like the already tattooed. The former's estimates that $52 \%$ of their friends and $52 \%$ of the U.S. population are tattooed on average are similar and not significantly different from those of the hidden tattooed. On the other hand, the non-tattooed who are less likely to get a tattoo in the coming year estimate substantially lower percentages of tattoos among their friends (28\%) and the U.S. population (35\%). ${ }^{30}$ These orderings of percentage friends and Americans with tattoos by tattoo status and by the likelihood

\footnotetext{
${ }^{28}$ For each of these three motives, the percentages of visibles and hiddens that cite the motive are similar to one another, never differing by more than 1.5 percentage points.

29 This is consistent with MacKinnon et al. (2011) who show that people choose to associate more closely with others who share even peripheral physical similarities like wearing glasses and hair color. Tattoos were not considered.

${ }^{30}$ See Table 15 for more summary statistics by tattoo subgroup and for statistical tests.
} 
of getting a tattoo in the coming year continue to hold for male subjects only as well as for female subjects only, although women estimate higher percentages of friends and Americans with tattoos than men do for each category.

Next, we present evidence that the tattooed underestimate the potentially detrimental effects of a tattoo in the workplace comes from a scenario we presented to subjects. All subjects were asked to imagine that an acquaintance is applying for a job as a hotel manager. ${ }^{31}$ The job ad states that the qualified job applicant will possess the following qualifications: extensive experience in hotel operations; computer literacy and experience with Windows OS and software; a college/university degree; strong interpersonal skills; be highly responsible and reliable. The subject is asked to evaluate how a shortcoming in each of these five qualifications as well as a number of other factors will help or hinder the subject's acquaintance in getting hired, where 1 is "extremely helpful”, 5 equates to "neither helpful nor harmful” and 9 is "extremely harmful." On the one hand, the non-tattooed, hiddens and visibles all recognize that "visible tattoos" are harmful as indicated by their mean ratings significantly greater than $5(p<.01$ in one-sided t-tests of means). On the other hand, both the hiddens and the visibles rated them as significantly less harmful (mean scores of 6.24 and 6.16, respectively) than did the non-tattooed (mean $=6.74)(p<$ .01 from Kruskal-Wallis test and from both pairwise Wilcoxon tests). ${ }^{32}$ This is particularly notable when contrasted with the lack of significant differences in the evaluation distributions by tattoo status for the vast majority of the qualifications and other factors we considered.

From our incentivized time-preferences experiment and CRT test, we already know that more short-sighted and more impulsive subjects are more likely to have a tattoo. Does the tattooeds' demonstrated blind spot with respect to the prevalence and acceptance of tattoos provide an independent explanation for the decision to get tattooed?

Table 16 reports the results from ordered probit regressions with the dependent measure, tattoo status, equal to 0 if the subject does not have a tattoo, 1 if he has only readily hidden tattoos and 2 if he has at least one visible tattoo. Regression (18) confirms that the later the subject switches to Option B in the time-preferences task, the more likely he is to have a tattoo and that subjects who answer correctly three or four CRT questions are significantly less likely to have a

\footnotetext{
${ }^{31}$ The exact wording of the scenario and response categories appear in the Appendix.

${ }^{32}$ Interestingly, with a mean rating of only 5.75, the non-tattooed who intend to get a tattoo in the coming year regard visible tattoos as the least harmful of any subgroup and only marginally significantly greater than $5(p=.06)$.
} 
tattoo than those who got all four questions wrong. The extent to which subjects care about what others think of them is not a significant predictor of tattoo status $(p=.34)$, whereas all three of the tattoo prevalence and awareness variables are significantly different from zero in the predicted directions. The less harmful one considers a visible tattoo in the hiring scenario, the more tattooed friends one has and the higher percentage of the U.S. population one believes to be tattooed, the more likely one is to have a tattoo. In fact, increasing a subject's percentage of tattooed friends by 19 percentage points is associated with an upward shift in tattoo status similar in magnitude as going from zero to three or four correctly answered CRT questions.

The signs and (lack of) significance remain largely unchanged when our series of sociodemographic and risk controls are included in regression (19). Only subjects' estimates of the percentage of Americans with a tattoo is no longer significant $(p=.14)$. Males, frequent churchgoers and those in the very highest income category are all significantly less likely to report having a tattoo. Age on its own is not significantly different from zero. However, as discussed in section 3.1 and seen in Figure 2, the relationship between tattoo incidence and age is non-monotonic, peaking at 38\% among 32-40 year-olds. Indeed, when age ${ }^{2}$ is also included in the regression a significant inverted-U shape relationship is found between age and the likelihood of a tattoo.

To return to the question in the heading of this subsection, the tattooed are not fully aware of the reality of tattoos and it is precisely those individuals least aware that are most likely to get tattooed. These findings are consistent with this paper's theme that the tattooed are short-sighted and attest to a form of myopia with regard to tattoos in society at large. The tattooed substantially overestimate their prevalence in the population, and are less concerned about the potentially harmful effects of finding employment. Even if tattoos are normative among one's friends, a farsighted individual looks beyond his social circle when contemplating a decision with possible career repercussions.

\section{Conclusions}

Our paper reports experimental and survey evidence that having at least one hidden tattoo and, even more so, a visible tattoo are persistent predictors of present-oriented preferences, shortsightedness and impulsivity. It is striking that the mere fact that one has a tattoo is associated with short-sightedness when other pertinent attributes of one’s tattoo(s) are not. In particular, neither 
the number of tattoos, the motive for getting a tattoo, the time elapsed since one's most recent tattoo nor the age at which one was first tattooed is a significant predictor of time preferences.

To be clear, we do not condone discrimination on the basis of tattoos. Discrimination may also be costly to employers who needlessly pass over qualified employees. Moreover, tattoos have come to be so normative among younger Americans that they reveal far less about personality traits than they once did (Swami et al. 2016). Notwithstanding, tattooing still seems to reveal two employment-relevant traits - short-sightedness and impulsivity - even while they convey little about other traits about which employers may maintain stereotypes. Some employers may discriminate against the tattooed on the basis of antiquated stereotypes, while others may have intuited the link between tattooing and the failure to consider long-term costs. Could this be a reason for employer discrimination against the tattooed?

If so, we would expect to find high levels of discrimination in occupations in which patience and planning skills are valued and less or possibly no discrimination in occupations in which instinctive, quick decision-making takes precedence. This is a promising topic for a future, in-depth empirical study. In the meantime, there appears to be at least some anecdotal support for this distinction. Internet forums are replete with advice to prospective medical students not to get tattoos and to consider seriously tattoo removal. One reason expressed is tattoos will detract from doctors' professionalism in the eyes of their patients. Indeed, subjects react significantly more negatively to a tattooed doctor than to a tattooed auto mechanic (Baumann et al. 2015). On the other hand, tattoos are highly normative among professional athletes, artists, actors and bartenders. While all of these occupations are also in the public eye, they are ones in which spontaneity may be regarded as an asset.

If visible tattoos invite discrimination in some professions, then they may be ill-advised. Yet economists shy away from interfering with others' preferences, including their expressions of individuality. Under the guise of paternalism, banning the use of illicit drugs, drinking and driving, and other harmful behaviors number among the exceptions. But, discouraging tattoos is tantamount to encouraging minorities to conceal their minority status: it represses the victim of discrimination while ignoring the bigoted views of the perpetrator of the discriminatory behavior. A pragmatic policy compromise would be to encourage those desiring a tattoo to get a readily 
hidden one, at least until they are well established in their careers. ${ }^{33}$ This advice seems sensible given that nothing in U.S. law prevents employers from discriminating against tattooed job candidates. At the same time, the continued emphasis in our education system on fostering tolerance and respect for diversity in all its forms, including fashion choices, seems paramount in our increasingly global community.

\section{References}

Anderhub, Vital, Werner Güth, Uri Gneezy, and Doron Sonsino (2001) "On the interaction of risk and time preferences: An experimental study,” German Economic Review 2:3, 239-253.

Andersen, Steffen, Glenn W. Harrison, Morten I. Lau, and E. Elisabet Rutström (2008) "Eliciting risk and time preferences,” Econometrica 76:3, 583-618.

Anderson, Monica, and Andrew Perrin (2016, September 7) “13\% of Americans don’t use the internet. Who are they?” retrieved on November 1, 2017 from http://www.pewresearch.org/facttank/2016/09/07/some-americans-dont-use-the-internet-who-are-they/.

Andreoni, James, and Charles Sprenger (2012) "Risk preferences are not time preferences,” American Economic Review 102:7, 3357-3376.

Arndt, Aaron D., and Myron N. Glassman (2012) "What tattoos tell customers about salespeople: The role of gender norms,” Marketing Management Journal 22:1, 50-65.

Baumann, Chris, Andrew R. Timming, and Paul J. Gollan (2016) “Taboo tattoos? A study of the gendered effects of body art on consumers' attitudes toward visibly tattooed front line staff,” Journal of Retailing and Consumer Services 29, 31-39.

Braithwaite, Ronald, Alyssa Robillard, Tammy Woodring, Torrence Stephens, and Kimberly Jacob Arriola (2001) "Tattooing and body piercing among adolescent detainees: relationship to alcohol and other drug use,” Journal of Substance Abuse 13:1, 5-16.

Brallier, Sara A., Maguire, Karen A., Smith, Daniel A., and Palm, Linda J. (2011) "Visible tattoos and employment in the restaurant service industry,” International Journal of Business and Social Science 2:6, 72-76.

Brañas-Garza, Pablo, Praveen Kujal, and Balint Lenkei (2015) "Cognitive Reflection Test: whom, how, when,” unpublished manuscript.

\footnotetext{
33 This advice corresponds to that given by numerous career counselling websites, such as Vault.com discussed in footnote 2 .
} 
Carmen, Rachael A., Amanda E. Guitar, and Haley M. Dillon (2012) "Ultimate answers to proximate questions: The evolutionary motivations behind tattoos and body piercings in popular culture,” Review of General Psychology 16:2, 134-143.

Coller, Maribeth, and Melonie B. Williams (1999) "Eliciting individual discount rates," Experimental Economics 2:2, 107-127.

Corgnet, Brice, Antonio M. Espín, Roberto Hernán-González, Praveen Kujal, and Stephen Rassenti (2016) “To trust, or not to trust: cognitive reflection in trust games," Journal of Behavioral and Experimental Economics 64, 20-27.

Deschesnes, Marthe, Philippe Finès, and Stephanie Demers (2006) “Are tattooing and body piercing indicators of risk-taking behaviours among high school students?” Journal of Adolescence 29:3, 379-393.

Dillingh, Rik, Peter Kooreman, and Jan Potters (2016) “Tattoos, Life Style and the Labor Market,” unpublished manuscript.

Drimmer, Frederick. Very special people: The struggles, loves, and triumphs of human oddities. Bell Publishing Company, 1985.

Eckel, Catherine, Cathleen Johnson, and Claude Montmarquette (2005) "Saving decisions of the working poor: Short-and long-term horizons," in Field experiments in economics, Emerald Group Publishing Limited, 219-260.

Enriquez, Juan. (2013) "Your online life, permanent as a tattoo," TED Conferences. http://www.ted.com/talks/juan_enriquez_how_to_think_about_digital_tattoos.

French, M. T., Maclean, J. C., Robins, P. K., Sayed, B., and Shiferaw, L. (2016) “Tattoos, Employment, and Labor Market Earnings: Is There a Link in the Ink?” Southern Economic Journal 82:4, 121-1246.

Harrison, Glenn W., Morten I. Lau, and Melonie B. Williams (2002) "Estimating individual discount rates in Denmark: A field experiment,” American Economic Review 92:5, 1606-1617.

Hong, Fuhai, Wei Huang, and Xiaojian Zhao (2016) "Sunk Cost as a Self-Management Device,” unpublished manuscript.

Hoppe, Eva I., and David J. Kusterer (2011) "Behavioral biases and cognitive reflection,” Economics Letters 110:2 97-100.

Horowitz, John K. (1991) “Discounting money payoffs: An experimental analysis,” Handbook of Behavioral Economics 309-324. 
Koch, Jerome R., Alden E. Roberts, Myrna L. Armstrong, and Donna C. Owen (2004) "Correlations of religious belief and practice with college students' tattoo-related behavior,” Psychological Reports 94:2, 425-430.

Kosmin, Barry A., Ariela Keysar, Ryan Cragun, and Juhem Navarro-Rivera (2009) “American nones: The profile of the no religion population, a report based on the American religious identification survey 2008.”

Lane, David C. (2014) “Tat's All Folks: An Analysis of Tattoo Literature," Sociology Compass 8:4, 398-410.

Laumann, Anne E., and Amy J. Derick (2006) “Tattoos and body piercings in the United States: a national data set,” Journal of the American Academy of Dermatology 55:3, 413-421.

Loewenstein, George and Richard H. Thaler (1989) “Anomalies: intertemporal choice,” Journal of Economic Perspectives 3:4, 181-193.

MacKinnon, Sean P., Jordan, Christian H., and Wilson, Anne E. (2011) "Birds of a feather sit together: Physical similarity predicts seating choice,” Personality and Social Psychology Bulletin 37, 879 - 892.

Oechssler, Jörg, Roider, Andreas, and Schmitz, Patrick W. (2009) "Cognitive abilities and behavioral biases,” Journal of Economic Behavior and Organization 72:1, 147-152.

Shah, Anuj K., Sendhil Mullainathan, and Eldar Shafir (2012) "Some consequences of having too little,” Science 338:6107, 682-685.

Sinha-Roy, Piya (2012, March 5) “Tattooed women outnumber men in a new poll,” Reuters.

Swami, Viren, Ulrich S. Tran, Tim Kuhlmann, Stefan Stieger, Helen Gaughan, Martin Voracek (2016) "More similar than different: Tattooed adults are only slightly more impulsive and willing to take risks than Non-tattooed adults," Personality and Individual Differences 88, 40-44.

Swami, Viren, and Adrian Furnham (2007) "Unattractive, promiscuous and heavy drinkers: Perceptions of women with tattoos,” Body Image 4:4, 343-352.

Thaler, Richard (1981) "Some empirical evidence on dynamic inconsistency," Economics Letters 8:3, 201-207.

The Record (2012, November 17) “Tattoo removal is expensive, time-consuming and painful. It's also a booming industry,” retrieved on November 1, 2017 from https://www.therecord.com/livingstory/2615521-tattoo-removal-is-expensive-time-consuming-and-painful-it-s-also-a-boomingindustry/.

Tiggemann, Marika, and Fleur Golder (2006) "Tattooing: An expression of uniqueness in the appearance domain,” Body Image 3:4, 309-315. 
Vault.com "How to make a good impression," retrieved on November 1, 2017 from http://www.vault.com/interviews/article/interviewing/how-to-make-a-good-impression/.

Weber, Elke U., Ann-Renee Blais, and Nancy E. Betz (2002) “A domain-specific risk-attitude scale: Measuring risk perceptions and risk behaviors," Journal of Behavioral Decision Making 15:4, 263-290.

York College of Pennsylvania (2013) "National Professionalism Survey - Workplace Report," available at https://www.ycp.edu/media/york-website/cpe/York-College-Professionalism-in-theWorkplace-Study-2013.pdf.

Zellner, Arnold (1962) "An efficient method of estimating seemingly unrelated regressions and tests for aggregation bias,” Journal of the American statistical Association 57:298, 348-368. 
Figure 1: Histograms of switch to Option B by Tattoo Status

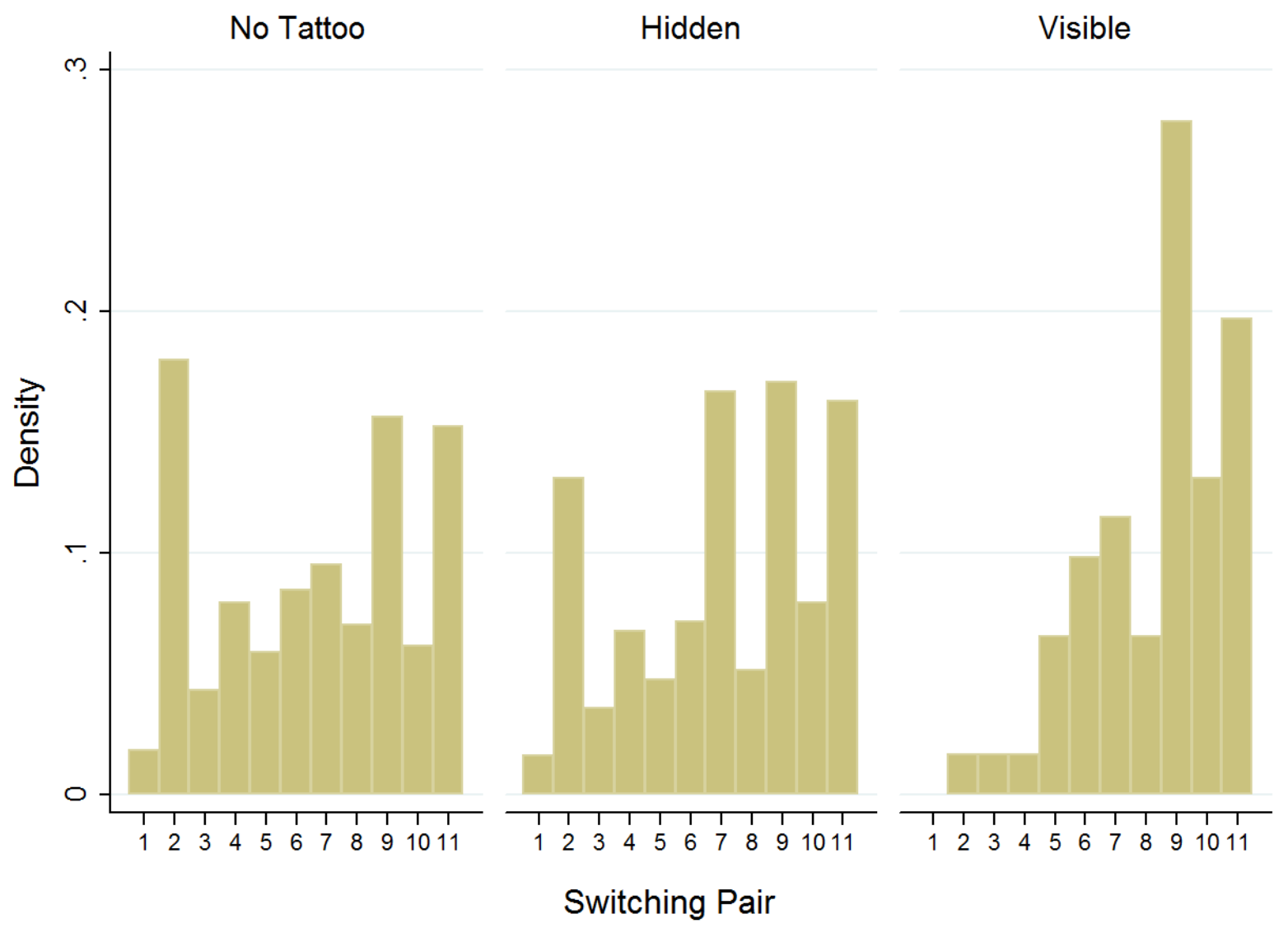

Notes: Histograms of the pair at which subjects switch from Option A (\$1 payable in 18 hours) to Option B (an ever-increasing amount payable in 3 weeks). The choice never to switch to Option B is coded as pair 11. 


\section{Figure 2: Percentage of Tattooed by Switching Pair and Age Cohort}

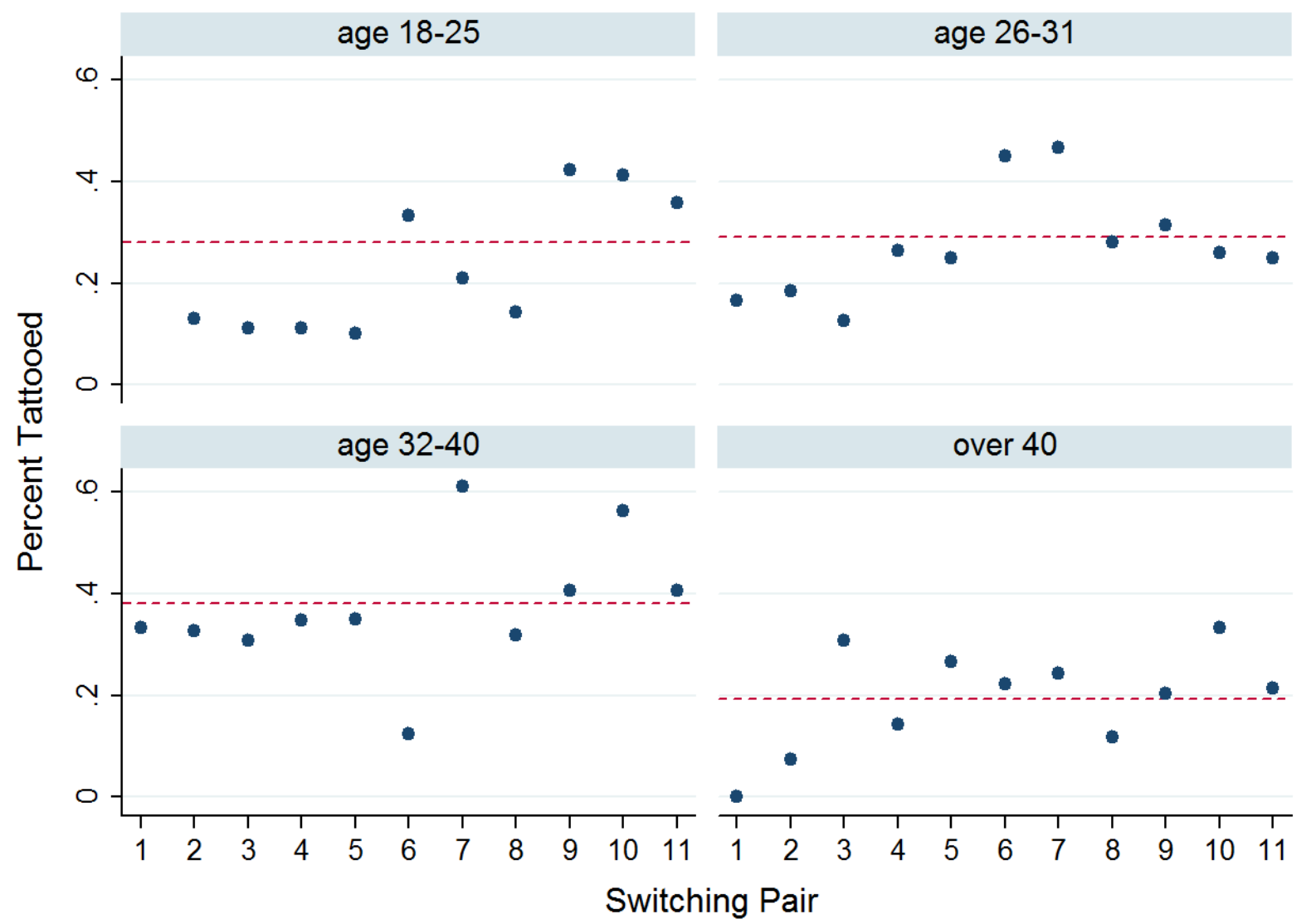

Notes: The dashed line indicates the fraction of tattooed subjects in the given age cohort. For each switching pair (1 through 11), the height of the dot shows the fraction of tattooed subjects among the total number of subjects that switched from Option A to Option B at this pair. 
Figure 3: Mean Switching Pair by Likelihood of getting a Tattoo within a year

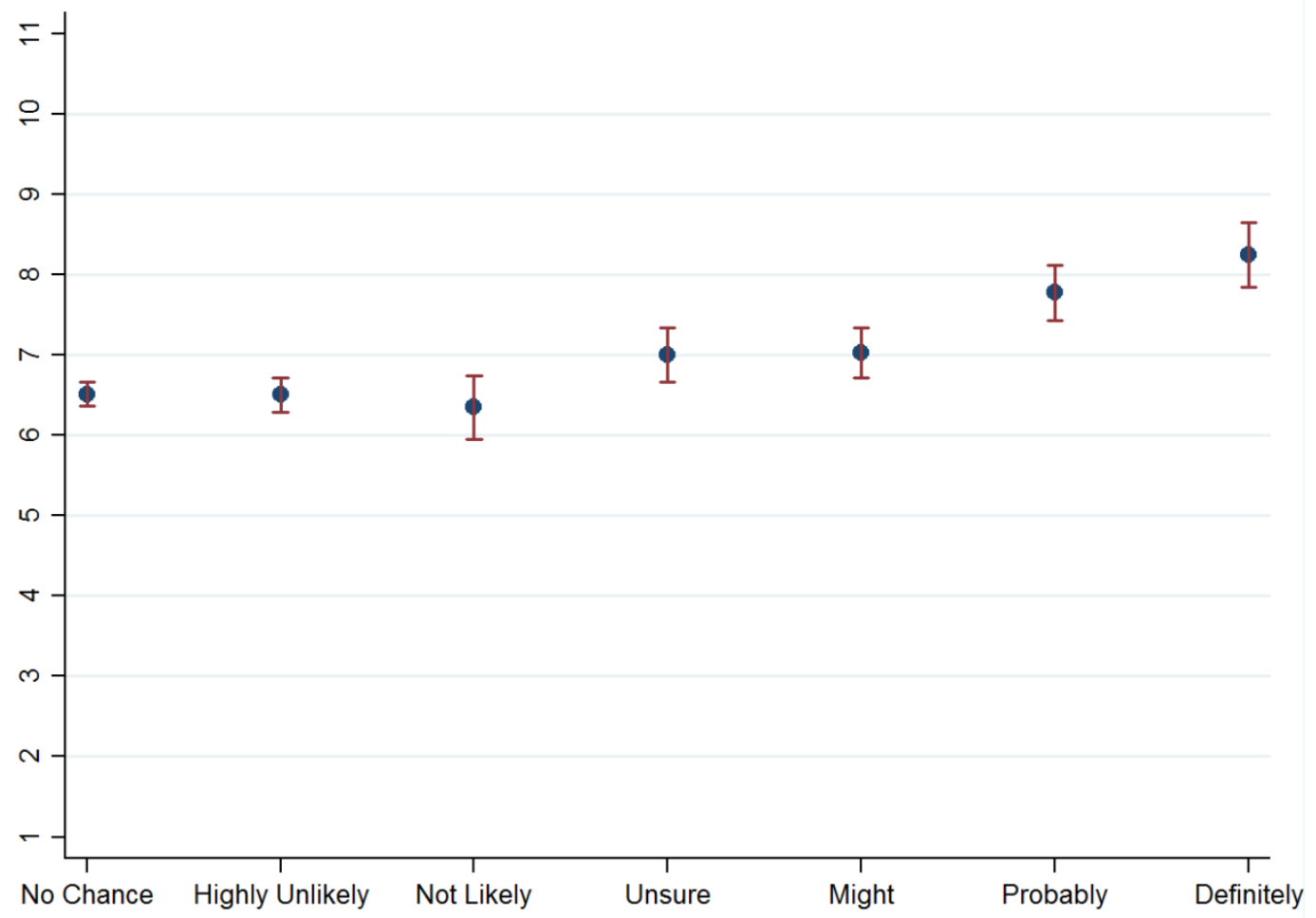

Figure 4: Mean Switching Pair by Likelihood of getting a Tattoo within a year by tattoo status

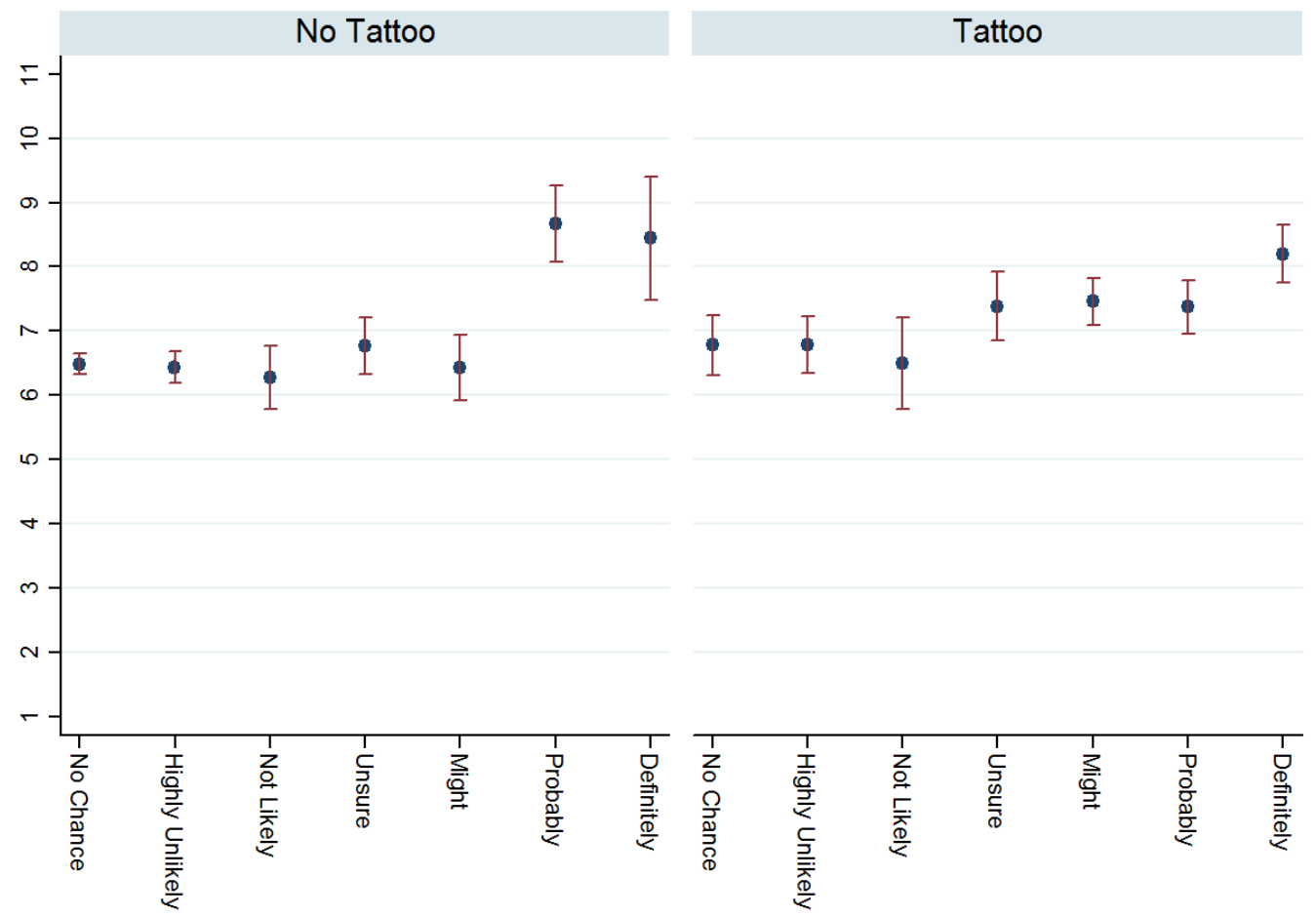


Table 1: Incentivized Time-Preferences Experiment

\begin{tabular}{|c|c|c|}
\hline Pair & Option A & Option B \\
\hline 1 & $\$ 1$ in 18 hours & $\$ 1$ in 3 weeks \\
\hline 2 & $\$ 1$ in 18 hours & $\$ 1.05$ in 3 weeks \\
\hline 3 & $\$ 1$ in 18 hours & $\$ 1.10$ in 3 weeks \\
\hline 4 & $\$ 1$ in 18 hours & $\$ 1.20$ in 3 weeks \\
\hline 5 & $\$ 1$ in 18 hours & $\$ 1.30$ in 3 weeks \\
\hline 6 & $\$ 1$ in 18 hours & $\$ 1.45$ in 3 weeks \\
\hline 7 & $\$ 1$ in 18 hours & $\$ 1.65$ in 3 weeks \\
\hline 8 & $\$ 1$ in 18 hours & $\$ 1.90$ in 3 weeks \\
\hline 9 & $\$ 1$ in 18 hours & $\$ 2.20$ in 3 weeks \\
\hline 10 & $\$ 1$ in 18 hours & $\$ 2.50$ in 3 weeks \\
\hline
\end{tabular}

Table 2: Summary Statistics by Tattoo Status

Panel A: Socio-demographic characteristics

\begin{tabular}{|c|c|c|c|c|c|c|c|}
\hline \multirow{2}{*}{ Variable } & \multicolumn{2}{|c|}{ No Tattoo } & \multicolumn{2}{|c|}{ Hidden } & \multicolumn{2}{|c|}{ Visible } & \multirow{2}{*}{$\begin{array}{c}\text { Kruskal-Wallis } \\
\chi^{2}(2), p \text {-value }\end{array}$} \\
\hline & Full & Restricted & Full & Restricted & Full & Restricted & \\
\hline Female & $\begin{array}{c}.41 \\
(.49)\end{array}$ & $\begin{array}{c}.41 \\
(.49)\end{array}$ & $\begin{array}{l}.62 \\
(.49)\end{array}$ & $\begin{array}{c}.62 \\
(.49)\end{array}$ & $\begin{array}{l}.65 \\
(.48)\end{array}$ & $\begin{array}{c}.70 \\
(.46)\end{array}$ & $\begin{array}{c}42.5 \\
p<.01\end{array}$ \\
\hline Age (years) & $\begin{array}{c}35.6 \\
(11.2)\end{array}$ & $\begin{array}{c}35.6 \\
(11.2)\end{array}$ & $\begin{array}{l}33.8 \\
(8.3)\end{array}$ & $33.9(8.3)$ & $\begin{array}{l}32.5 \\
(8.8)\end{array}$ & $\begin{array}{l}33.1 \\
(9.0)\end{array}$ & $\begin{array}{c}4.3 \\
p=.12\end{array}$ \\
\hline Education & $\begin{array}{c}2.80 \\
(0.64)\end{array}$ & $\begin{array}{c}2.79 \\
(0.64)\end{array}$ & $\begin{array}{c}2.73 \\
(0.61)\end{array}$ & $\begin{array}{c}2.72 \\
(0.61) \\
\end{array}$ & $\begin{array}{c}2.60 \\
(0.63)\end{array}$ & $\begin{array}{c}2.56 \\
(0.62)\end{array}$ & $\begin{array}{c}7.5 \\
p=.02\end{array}$ \\
\hline Income & $\begin{array}{c}3.46 \\
(1.51)\end{array}$ & $\begin{array}{c}3.44 \\
(1.51)\end{array}$ & $\begin{array}{c}3.41 \\
(1.44)\end{array}$ & $\begin{array}{c}3.41 \\
(1.43)\end{array}$ & $\begin{array}{c}3.16 \\
(1.47)\end{array}$ & $\begin{array}{c}3.07 \\
(1.31)\end{array}$ & $\begin{array}{c}3.9 \\
p=.14\end{array}$ \\
\hline Employed F/T & $63.5 \%$ & $63.2 \%$ & $61.2 \%$ & $61.1 \%$ & $57.4 \%$ & $57.4 \%$ & \multirow{5}{*}{$\begin{array}{c}2.6 \\
p=.27\end{array}$} \\
\hline Employed P/T & $16.3 \%$ & $16.3 \%$ & $17.3 \%$ & $17.1 \%$ & $19.1 \%$ & $18.0 \%$ & \\
\hline Retired & $2.6 \%$ & $2.5 \%$ & $2.0 \%$ & $2.0 \%$ & $1.5 \%$ & $1.6 \%$ & \\
\hline Unemployed & $13.2 \%$ & $13.4 \%$ & $16.5 \%$ & $16.7 \%$ & $14.7 \%$ & $14.8 \%$ & \\
\hline Student & $4.5 \%$ & $4.6 \%$ & $3.1 \%$ & $3.2 \%$ & $7.4 \%$ & $8.2 \%$ & \\
\hline $\begin{array}{l}\text { Strength of } \\
\text { Religious Beliefs }\end{array}$ & $\begin{array}{c}3.12 \\
(2.24)\end{array}$ & $\begin{array}{c}3.08 \\
(2.23)\end{array}$ & $\begin{array}{c}2.87 \\
(2.15)\end{array}$ & $\begin{array}{c}2.87 \\
(2.16)\end{array}$ & $\begin{array}{c}3.40 \\
(2.21)\end{array}$ & $\begin{array}{c}3.21 \\
(2.19)\end{array}$ & $\begin{array}{c}3.6 \\
p=.17\end{array}$ \\
\hline $\begin{array}{l}\text { Church } \\
\text { Attendance }\end{array}$ & $\begin{array}{c}2.10 \\
(1.64)\end{array}$ & $\begin{array}{c}2.06 \\
(1.60)\end{array}$ & $\begin{array}{c}1.82 \\
(1.38)\end{array}$ & $\begin{array}{c}1.81 \\
(1.37)\end{array}$ & $\begin{array}{c}2.10 \\
(1.73)\end{array}$ & $\begin{array}{c}1.79 \\
(1.38) \\
\end{array}$ & $\begin{array}{c}4.7 \\
p=.09\end{array}$ \\
\hline Belief in God & $\begin{array}{c}3.69 \\
(2.50)\end{array}$ & $\begin{array}{c}3.65 \\
(2.50)\end{array}$ & $\begin{array}{c}3.53 \\
(2.39)\end{array}$ & $\begin{array}{c}3.54 \\
(2.40)\end{array}$ & $\begin{array}{c}4.29 \\
(2.37)\end{array}$ & $\begin{array}{c}4.16 \\
(2.42)\end{array}$ & $\begin{array}{l}5.1 \\
=.08\end{array}$ \\
\hline Risk-taker & $\begin{array}{c}5.88 \\
(2.61)\end{array}$ & $\begin{array}{c}5.87 \\
(2.61)\end{array}$ & $\begin{array}{c}6.13 \\
(2.66)\end{array}$ & $\begin{array}{c}6.12 \\
(2.66)\end{array}$ & $\begin{array}{c}6.66 \\
(2.66)\end{array}$ & $\begin{array}{c}6.57 \\
(2.75)\end{array}$ & $\begin{array}{c}6.6 \\
p=.04\end{array}$ \\
\hline
\end{tabular}

Notes: For each tattoo status, the left column reports the mean (s.d.) of the socio-demographic controls for the full sample $(\mathrm{n}=1104)$, while the right column excludes subjects who made multiple switches in the time-preferences experiment $(\mathrm{n}=1080)$. Education, Income, Strength of Religious Beliefs, Church Attendance and Belief in God are categorical variables. Higher values correspond to more of the reported characteristic. The distribution of Employment Status is broken down according to full-time (F/T) employment, part-time (P/T) employment, retired, unemployed and student. The values of the willingness-to-take-risks question range from 0 (not willing) to 10 (very willing). See the Appendix for the questions and response categories. The Kruskal-Wallis test results are based on the full sample. 
Panel B: Time Preferences by Tattoo Status

\begin{tabular}{|l|c|c|c|}
\hline Choice & No Tattoo & Hidden & Visible \\
\hline \% Switch (Pairs 1-10) & $83.2 \%$ & $82.8 \%$ & $72.1 \%$ \\
\hline \% Never Switch (Pair 11) & $15.0 \%$ & $16.1 \%$ & $17.7 \%$ \\
\hline \% Multiple Switches & $1.8 \%$ & $1.2 \%$ & $10.3 \%$ \\
\hline Mean Switching Pair & $6.56(3.22)$ & $7.02(3.06)$ & $8.38(2.21)$ \\
\hline
\end{tabular}

Notes: Distribution of switching choices (first three rows) and mean switching pair (s.d.) (fourth row).

Table 3: Other Measures of Short-Sightedness

\begin{tabular}{|c|l|c|c|c|}
\hline Domain & Question & No Tattoo & Tattoo - Hidden & Tattoo - Visible \\
\hline \multirow{3}{*}{ Financial } & No Retirement Savings & $\mathbf{1 . 0 4}(\mathbf{0 . 7 3})$ & $1.13(0.70)$ & $1.22(0.75)$ \\
\cline { 2 - 5 } & Late credit card & $\mathbf{1 . 5 2 ( 0 . 9 5 )}$ & $1.63(0.99)$ & $1.66(1.09)$ \\
\cline { 2 - 5 } & Poor Finances & $\mathbf{2 . 0 5 ( 0 . 8 2 )}$ & $2.18(0.75)$ & $2.10(0.69)$ \\
\hline \multirow{3}{*}{ Health } & Overeat & $2.20(1.10)$ & $2.27(1.17)$ & $2.43(1.29)$ \\
\cline { 2 - 5 } & No Exercise & $2.46(1.21)$ & $2.52(1.17)$ & $2.28(1.22)$ \\
\cline { 2 - 5 } & Alcohol & $\mathbf{1 . 9 6 ( 1 . 1 6 )}$ & $2.26(1.28)$ & $2.25(1.41)$ \\
\cline { 2 - 5 } & Smoke & $\mathbf{0 . 7 2 ( 1 . 0 6 )}$ & $\mathbf{1 . 2 0 ( 1 . 1 6 )}$ & $\mathbf{1 . 5 0 ( 1 . 1 4 )}$ \\
\hline \multirow{3}{*}{ Social } & Personal & $\mathbf{3 . 3 6}(\mathbf{2 . 1 0})$ & $\mathbf{4 . 1 1}(\mathbf{2 . 4 3 )}$ & $\mathbf{4 . 3 4 ( 2 . 5 7 )}$ \\
\cline { 2 - 5 } & Controversial & $\mathbf{4 . 1 2 ( 2 . 6 1 )}$ & $\mathbf{4 . 5 5 ( 2 . 6 2 )}$ & $\mathbf{5 . 3 1 ( 2 . 6 8 )}$ \\
\cline { 2 - 5 } & Good Time & $2.26(1.55)$ & $2.33(1.44)$ & $\mathbf{2 . 7 9 ( 1 . 7 4 )}$ \\
\hline
\end{tabular}

Notes: Entries are mean responses (standard deviations) to the indicated question. Exact questions appear in the Appendix. Bold entries are significantly different from the others (Wilcoxon-Mann-Whitney rank-sum test).

Table 4: CRT - Percent Correct by Tattoo Status

\begin{tabular}{|c|l|c|c|c|c|c|c|c|c|c|}
\hline \multirow{2}{*}{ Question } & Topic & \multicolumn{3}{|c|}{ No Tattoo } & \multicolumn{3}{c|}{ Hidden Tattoo } & \multicolumn{3}{c|}{ Visible Tattoo } \\
\cline { 2 - 11 } & Correct & Intuitive & Wrong & Correct & Intuitive & Wrong & Correct & Intuitive & Wrong \\
\hline CRT 1 & $\begin{array}{l}\text { Hamburger \& } \\
\text { Fries }\end{array}$ & $47.9 \%$ & $49.3 \%$ & $2.8 \%$ & $35.7 \%$ & $62.0 \%$ & $2.4 \%$ & $22.1 \%$ & $66.2 \%$ & $11.8 \%$ \\
\hline CRT 2 & $\begin{array}{l}\text { Spanish moss } \\
\text { doubles }\end{array}$ & $62.9 \%$ & $28.2 \%$ & $9.0 \%$ & $54.9 \%$ & $37.7 \%$ & $7.5 \%$ & $33.8 \%$ & $52.9 \%$ & $13.2 \%$ \\
\hline CRT 3 & $\begin{array}{l}5 \text { printers, } \\
5 \text { minutes }\end{array}$ & $59.9 \%$ & $31.9 \%$ & $8.2 \%$ & $49.4 \%$ & $36.9 \%$ & $13.7 \%$ & $39.7 \%$ & $45.6 \%$ & $14.7 \%$ \\
\hline CRT 4 & $\begin{array}{l}\text { Pass 96 } \\
\text { position }\end{array}$ & $56.5 \%$ & $39.1 \%$ & $4.5 \%$ & $45.5 \%$ & $49.4 \%$ & $5.1 \%$ & $45.6 \%$ & $45.6 \%$ & $8.8 \%$ \\
\hline All Correct & \multicolumn{3}{|c|}{$30.2 \%$} & & \multicolumn{3}{c|}{$21.2 \%$} & \multicolumn{3}{c|}{$13.2 \%$} \\
\hline All Incorrect & \multicolumn{3}{|c|}{$17.3 \%$} & \multicolumn{3}{c|}{$26.7 \%$} & \multicolumn{3}{c|}{$38.2 \%$} \\
\hline
\end{tabular}

Notes: For each of the four CRT questions, the entries indicate the percentages of subjects who answered the question correctly; who gave the intuitive, but incorrect answer; and who gave an unintuitive, incorrect answer, by tattoo status. The percentages of subjects that answered all 4 correctly (“All Correct”) and all 4 incorrectly (“All Incorrect”) are also given. 
Table 5: OLS regressions on switching pair

\begin{tabular}{|c|c|c|c|c|c|c|c|}
\hline Variable & $(1)$ & $(2)$ & (3) & $(4)$ & (5) & (6) & $(7)$ \\
\hline Hidden & $\begin{array}{l}0.46 * * \\
(0.23)\end{array}$ & $\begin{array}{l}0.47 * * \\
(0.23)\end{array}$ & $\begin{array}{l}0.53^{* *} \\
(0.24)\end{array}$ & $\begin{array}{l}0.51 * * \\
(.024)\end{array}$ & $\begin{array}{c}0.33 \\
(0.25)\end{array}$ & $\begin{array}{c}0.25 \\
(0.25)\end{array}$ & $\begin{array}{l}0.79 * * \\
(0.39)\end{array}$ \\
\hline Visible & $\begin{array}{c}1.82^{* * * *} \\
(0.30)\end{array}$ & $\begin{array}{c}1.87^{* * * *} \\
(0.32)\end{array}$ & $\begin{array}{c}1.99^{* * * *} \\
(0.38)\end{array}$ & $\begin{array}{c}1.91^{* * *} \\
(0.38)\end{array}$ & $\begin{array}{c}1.72 * * * \\
(0.40)\end{array}$ & $\begin{array}{c}1.57^{* * * *} \\
(0.41)\end{array}$ & $\begin{array}{c}2.05^{* * * *} \\
(0.51)\end{array}$ \\
\hline Tattoos & - & $\begin{array}{l}-0.004 \\
(0.005)\end{array}$ & $\begin{array}{l}-0.029 \\
(0.035)\end{array}$ & $\begin{array}{l}-0.027 \\
(0.034)\end{array}$ & $\begin{array}{l}-0.024 \\
(0.032)\end{array}$ & $\begin{array}{l}-0.026 \\
(0.035)\end{array}$ & $\begin{array}{l}-0.017 \\
(0.034)\end{array}$ \\
\hline Tattoos $^{2}$ & - & - & $\begin{array}{c}0.000 \\
(0.000)\end{array}$ & $\begin{array}{c}0.000 \\
(0.000)\end{array}$ & $\begin{array}{c}0.000 \\
(0.000)\end{array}$ & $\begin{array}{c}0.000 \\
(0.000)\end{array}$ & $\begin{array}{c}0.000 \\
(0.000)\end{array}$ \\
\hline Take Risks & - & - & - & $\begin{array}{c}0.084^{* *} \\
(0.038) \\
\end{array}$ & $\begin{array}{c}0.093^{* *} \\
(0.039) \\
\end{array}$ & $\begin{array}{l}0.072^{*} \\
(0.040)\end{array}$ & $\begin{array}{c}0.092^{* *} \\
(0.040) \\
\end{array}$ \\
\hline 1 CRT correct & - & - & - & - & - & $\begin{array}{c}-0.66 * * \\
(0.32)\end{array}$ & - \\
\hline 2 CRT correct & - & - & - & - & - & $\begin{array}{l}-0.55^{*} \\
(0.33) \\
\end{array}$ & - \\
\hline 3 CRT correct & - & - & - & - & - & $\begin{array}{c}-0.64 * * \\
(0.32)\end{array}$ & - \\
\hline $\begin{array}{l}4 \text { (All) CRT } \\
\text { correct }\end{array}$ & - & - & - & - & - & $\begin{array}{c}-1.34 * * * \\
(0.31)\end{array}$ & - \\
\hline Constant & $\begin{array}{c}6.56 \\
(0.12) \\
\end{array}$ & $\begin{array}{r}6.56 \\
(0.12) \\
\end{array}$ & $\begin{array}{c}6.56 \\
(0.12) \\
\end{array}$ & $\begin{array}{c}6.06 \\
(0.25) \\
\end{array}$ & $\begin{array}{c}8.75 \\
(1.33) \\
\end{array}$ & $\begin{array}{c}9.18 \\
(1.28) \\
\end{array}$ & $\begin{array}{c}9.04 \\
(1.41) \\
\end{array}$ \\
\hline $\begin{array}{c}\text { Motives for } \\
\text { Tattoo included }\end{array}$ & No & No & No & No & No & No & Yes \\
\hline $\begin{array}{c}\text { Socio-demo } \\
\text { controls included }\end{array}$ & No & No & No & No & Yes & Yes & Yes \\
\hline $\mathrm{R}^{2}$ & .019 & .019 & .020 & .024 & .054 & .073 & .063 \\
\hline $\mathrm{N}$ & 1080 & 1080 & 1080 & 1080 & 1047 & 1047 & 1047 \\
\hline Hidden = Visible & $p<.01$ & $p<.01$ & $p<.01$ & $p<.01$ & $p<.01$ & $p<.01$ & $p<.01$ \\
\hline
\end{tabular}

Notes: Dependent variable: pair at which subject switched from Option A to Option B in incentivized time-preferences experiment. "Hidden" and "Visible" are indicators for whether the subject has tattoos, all of which can be readily hidden with clothing, or at least one visible tattoo, respectively. "Tattoos" and "Tattoos"” are the subject's number of tattoos and number of tattoos squared, respectively (equal to zero if not tattooed). Socio-demographic controls: age, sex, educational attainment, employment status, income, U.S. census region, strength of religious beliefs, church attendance. Regression (7) includes indicator variables for each of the ten motives for getting a tattoo as well as "other" (see the Appendix for the list of motives). Heteroskedasticity-robust standard errors in parentheses. The last row reports the $p$-value from a t-test of coefficients that Hidden $=$ Visible.

*** significant at the one-percent level.

** significant at the five-percent level.

* $\quad$ significant at the ten-percent level. 
Table 6: Distribution of Reasons for Getting a Tattoo

\begin{tabular}{|l|c|c|}
\hline Motive & Hidden & Visible \\
\hline Expression of Individuality & $119(46.7 \%)$ & $30(44.1 \%)$ \\
\hline Like the Way the Tattoo Looks & $119(46.7 \%)$ & $20(29.4 \%)$ \\
\hline Statement of Personal Identity & $90(35.3 \%)$ & $20(29.4 \%)$ \\
\hline Remember Particular Time & $77(30.2 \%)$ & $17(25.0 \%)$ \\
\hline Memorialize Loved One & $51(20.0 \%)$ & $11(16.2 \%)$ \\
\hline Impulsive Decision & $36(14.1 \%)$ & $11(16.2 \%)$ \\
\hline Create Certain Image of Me & $25(9.8 \%)$ & $8(11.8 \%)$ \\
\hline Other & $9(3.5 \%)$ & $7(10.3 \%)$ \\
\hline Most Friends are Tattooed & $9(3.5 \%)$ & $1(1.5 \%)$ \\
\hline Belong to Group who are Tattooed & $2(0.8 \%)$ & $3(4.4 \%)$ \\
\hline Political/Environmental Statement & $2(0.8 \%)$ & $2(2.9 \%)$ \\
\hline
\end{tabular}

Notes: Number of subjects (percentages) that selected each motive for getting their hidden tattoos and again separately for their visible tattoos. Percentages sum to greater than $100 \%$ because they could select more than one motive for each tattoo category.

Table 7: Seemingly Unrelated Regressions for different domains of Short-Sightedness

\begin{tabular}{|l|c|c|c|}
\hline Variable & Financial & Health & Social \\
\hline Hidden & $.126^{* * *}(.049)$ & $.178^{* * *}(.038)$ & $.138^{* * *}(.047)$ \\
\hline Visible & $.121(.086)$ & $.323^{* * *}(.067)$ & $.339^{* * *}(.082)$ \\
\hline Constant & $.185(.058)$ & $-.310(.046)$ & $-.508(.041)$ \\
\hline $\mathrm{N}$ & 1104 & 1104 & 1104 \\
\hline Hidden = Visible & $p=.96$ & $p=.04$ & $p=.02$ \\
\hline \multicolumn{4}{|c|}{ Breusch-Pagan test $\chi^{2}(2)=78.3, p<.01$} \\
\hline
\end{tabular}

Notes: Seemingly unrelated regressions on subject $i$ 's domain-specific standardized mean response for the financial, health and social domains. In addition to indicator variables for hidden and visible tattoos, domain-specific controls are included as regressors, but not reported. The second-to-last last row reports the $p$-value from Wald test of coefficients that Hidden = Visible. The Breusch-Pagan test rejects the independence of the residuals across the three equations. 
Table 8: Separate OLS regressions for Men and Women

\begin{tabular}{|l|c|c|}
\hline \multirow{2}{*}{\multicolumn{1}{c|}{ Variable }} & Men & Women \\
\cline { 2 - 3 } Hidden & $(8)$ & $(9)$ \\
& $0.67^{*}$ & -0.02 \\
\multirow{2}{*}{ Visible } & $(0.36)$ & $(0.32)$ \\
\hline \multirow{2}{*}{ Constant } & $1.92^{* * *}$ & $1.43^{* * *}$ \\
& $(0.54)$ & $(0.43)$ \\
\hline Risk, Socio-demo controls & 7.27 & 11.31 \\
\hline $\mathrm{R}^{2}$ & $(1.55)$ & $(0.90)$ \\
\hline $\mathrm{N}$ & Yes & Yes \\
\hline Hidden = Visible & .067 & .064 \\
\hline
\end{tabular}

Notes: See Table 5 Notes.

Table 9: CRT scores by Sex and Tattoo Status

\begin{tabular}{|l|c|c|c|c|c|c|}
\hline \multirow{2}{*}{ Variable } & \multicolumn{3}{|c|}{ Men } & \multicolumn{3}{c|}{ Women } \\
\cline { 2 - 7 } & No Tattoo & Hidden & Visible & No Tattoo & Hidden & Visible \\
\hline Out of 4 questions & $2.54(1.40)$ & $2.09(1.44)$ & $1.50(1.41)$ & $1.89(1.51)$ & $1.72(1.51)$ & $1.36(1.46)$ \\
\hline All 4 Correct & $35.1 \%$ & $24.7 \%$ & $16.7 \%$ & $22.9 \%$ & $19.1 \%$ & $11.4 \%$ \\
\hline All 4 Wrong & $12.1 \%$ & $18.6 \%$ & $29.1 \%$ & $24.8 \%$ & $31.2 \%$ & $43.2 \%$ \\
\hline
\end{tabular}

Notes: Mean number of correctly answered questions (s.d.) (first row). Percentage of subjects that answered all four CRT questions correctly and all four incorrectly (last two rows).

Table 10: How long contemplated first tattoo by Tattoo Status

\begin{tabular}{|l|c|c|}
\hline How long? & Hidden & Visible \\
\hline Spontaneous & $38(14.9 \%)$ & $12(17.7 \%)$ \\
\hline Day or two & $20(7.8 \%)$ & $8(11.8 \%)$ \\
\hline Several days & $19(7.5 \%)$ & $8(11.8 \%)$ \\
\hline Week or more & $29(11.4 \%)$ & $13(19.1 \%)$ \\
\hline At least a month & $79(31.0 \%)$ & $13(19.1 \%)$ \\
\hline More than year & $70(27.5 \%)$ & $14(20.6 \%)$ \\
\hline \multicolumn{2}{|c|}{ Wilcoxon-Mann-Whitney test $z=2.03, p=.04$} \\
\hline
\end{tabular}

Notes: Distributions of lengths of time respondents contemplated their first tattoo before getting it done by tattoo status. 
Table 11: Time contemplated first tattoo regression

\begin{tabular}{|l|c|}
\hline Variable & $(10)$ \\
\hline Visible & $1.47^{* * *}(0.35)$ \\
\hline Contemplate - Day or two & $-0.95(0.70)$ \\
\hline - Several days & $-1.23^{* *}(0.62)$ \\
\hline - Week or more & $-1.00(0.64)$ \\
\hline - At least a month & $-0.64(0.47)$ \\
\hline - More than year & $-0.47(0.51)$ \\
\hline Constant & $12.14(1.42)$ \\
\hline Risk, Socio-demo controls & Yes \\
\hline $\mathrm{R}^{2}$ & .169 \\
\hline $\mathrm{N}$ & 308 \\
\hline
\end{tabular}

Notes: See Table 5 Notes. “Contemplate” refers to how long subjects contemplated their first tattoo before getting it done. Indicator variables for five of the six response categories are included with "spontaneous" being the omitted category.

Table 12: Time elapsed since most recent tattoo regressions

\begin{tabular}{|l|c|c|}
\hline Variable & $(11)$ & $(12)$ \\
\cline { 1 - 2 } Visible & $1.29 * * *(0.39)$ & $1.41^{* * *}(0.36)$ \\
\cline { 1 - 2 } Most Recent Tattoo - Between 1-3 years ago & $0.47(0.63)$ & \multirow{2}{*}{-} \\
\cline { 1 - 2 } - Between 3-10 years ago & $-0.17(0.61)$ & $-0.21(0.78)$ \\
\hline - Between 10-20 years ago & $0.14(0.69)$ & $11.32(1.34)$ \\
\hline - More than 20 years ago & $-0.21(0.99)$ & Yes \\
\hline Constant & $1140(1.39)$ & .156 \\
\hline $\mathrm{R}^{2}$ Risk, Socio-demo controls & Yes & 308 \\
\hline $\mathrm{N}$ & .162 & 308 \\
\hline
\end{tabular}

Notes: See Table 5 Notes. "Most Recent Tattoo" refers to the timeframe in which subjects received their last tattoo. The omitted response category is "within the past year". 
Table 13: OLS regressions on Income

\begin{tabular}{|l|c|c|}
\hline Variable & $(13)$ & $(14)$ \\
\hline \multirow{2}{*}{ Hidden } & -.04 & .10 \\
& $(.11)$ & $(.09)$ \\
\hline \multirow{2}{*}{ Visible } & -.29 & -.12 \\
& $(.19)$ & $(.18)$ \\
\hline \multirow{2}{*}{ Switching Pair } & - & -.000 \\
& & $(.012)$ \\
\hline \multirow{2}{*}{ Constant } & 3.46 & 0.17 \\
& $(0.06)$ & $(0.41)$ \\
\hline Risk, Socio-demo controls & No & Yes \\
\hline $\mathrm{R}^{2}$ & .002 & .346 \\
\hline $\mathrm{N}$ & 1072 & 1047 \\
\hline
\end{tabular}

Notes: Dependent measure: subject $i$ 's reported net monthly income. The regressors include "Hidden" and "Visible" indicators for whether the subject has only readily hidden tattoos or at least one visible tattoo, respectively, and the subject's switching pair (regression (14)). See the Notes of Table 5 for the risk measure and set of socio-demographic controls.

Table 14: Likelihood of getting a tattoo within next year regressions

\begin{tabular}{|c|c|c|c|}
\hline Variable & (15) & (16) & (17) \\
\hline Hidden & - & $\begin{array}{c}0.13 \\
(0.24)\end{array}$ & - \\
\hline Visible & - & $\begin{array}{c}1.34^{* * *} \\
(0.34)\end{array}$ & - \\
\hline Tattoo & - & - & $\begin{array}{l}0.47 * * \\
(0.24)\end{array}$ \\
\hline Probably or Definitely Tattoo in next year & $\begin{array}{c}1.15^{* * *} \\
(0.30)\end{array}$ & $\begin{array}{c}0.92^{* * *} \\
(0.31)\end{array}$ & - \\
\hline $\begin{array}{l}\text { Probably or Definitely Tattoo in next year } \\
\text { \& No Tattoo }\end{array}$ & - & - & $\begin{array}{l}1.86^{* * *} \\
(0.55)\end{array}$ \\
\hline $\begin{array}{l}\text { Probably or Definitely Tattoo in next year } \\
\& \text { Tattoo }\end{array}$ & - & - & $\begin{array}{l}0.62^{*} \\
(0.36)\end{array}$ \\
\hline Constant & $\begin{array}{c}8.41 \\
(1.29)\end{array}$ & $\begin{array}{c}8.47 \\
(1.30)\end{array}$ & $\begin{array}{c}8.42 \\
(1.31)\end{array}$ \\
\hline Risk, Socio-demo controls & Yes & Yes & Yes \\
\hline $\mathrm{R}^{2}$ & .051 & .060 & .056 \\
\hline $\mathrm{N}$ & 1047 & 1047 & 1047 \\
\hline
\end{tabular}

Notes: See Table 5 Notes. "Tattoo" is an indicator variable for whether the subject has at least one tattoo, hidden or visible. "Probably or Definitely Tattoo in next year" equals one for subjects who responded that they "probably will” or "almost definitely will” get a tattoo within a year, and zero otherwise. In regression (9), this variable is interacted with whether the subject already has a tattoo ("Tattoo") or not ("No Tattoo"). 
Table 15: Summary Statistics related to caring, and perceptions of prevalence and adverse consequences of tattoos, by tattoo status and by likelihood of getting a tattoo within next year

\begin{tabular}{|c|c|c|c|c|c|c|c|}
\hline \multirow{2}{*}{ Variable } & \multicolumn{2}{|c|}{ No Tattoo } & \multicolumn{2}{|c|}{ Hidden } & \multicolumn{2}{|c|}{ Visible } & \multirow{2}{*}{$\begin{array}{c}\text { Kruskal-Wallis } \\
\chi^{2}, \mathbf{p} \text {-value }\end{array}$} \\
\hline & Unlikely & Likely & Unlikely & Likely & Unlikely & Likely & \\
\hline \multirow{2}{*}{$\begin{array}{l}\text { Care what } \\
\text { others think }\end{array}$} & \multicolumn{2}{|c|}{$\begin{array}{c}4.00 \\
(1.60)\end{array}$} & \multicolumn{2}{|c|}{$\begin{array}{c}3.78 \\
(1.65) \\
\end{array}$} & \multicolumn{2}{|c|}{$\begin{array}{c}4.13 \\
(1.61)\end{array}$} & $\begin{array}{l}\chi^{2}(2)=4.3 \\
p=.11\end{array}$ \\
\hline & $\begin{array}{c}3.99 \\
(1.59)\end{array}$ & $\begin{array}{c}4.07 \\
(1.96)\end{array}$ & $\begin{array}{c}3.82 \\
(1.64)\end{array}$ & $\begin{array}{c}3.65 \\
(1.71)\end{array}$ & $\begin{array}{c}4.13 \\
(1.53)\end{array}$ & $\begin{array}{c}4.13 \\
(1.79)\end{array}$ & $\begin{array}{l}\chi^{2}(5)=5.0 \\
p=.41\end{array}$ \\
\hline \multirow{2}{*}{$\begin{array}{l}\% \text { friends } \\
\text { with tattoos }\end{array}$} & \multicolumn{2}{|c|}{$\begin{array}{c}29.0 \\
(24.9)\end{array}$} & \multicolumn{2}{|c|}{$\begin{array}{c}55.3 \\
(27.6)\end{array}$} & \multicolumn{2}{|c|}{$\begin{array}{c}64.1 \\
(27.1)\end{array}$} & $\begin{array}{c}\chi^{2}(2)=202.5 \\
p<.01\end{array}$ \\
\hline & $\begin{array}{l}28.1 \\
(24.4)\end{array}$ & $\begin{array}{c}52.3 \\
(27.2)\end{array}$ & $\begin{array}{c}52.6 \\
(27.2)\end{array}$ & $\begin{array}{c}65.3 \\
(27.0)\end{array}$ & $\begin{array}{c}61.3 \\
(28.0)\end{array}$ & $\begin{array}{c}69.5 \\
(24.9)\end{array}$ & $\begin{array}{c}\chi^{2}(5)=228.8 \\
p<.01\end{array}$ \\
\hline \multirow{2}{*}{$\begin{array}{l}\text { \% U.S. pop'n } \\
\text { with tattoos }\end{array}$} & \multicolumn{2}{|c|}{$\begin{array}{c}36.0 \\
(19.1)\end{array}$} & \multicolumn{2}{|c|}{$\begin{array}{c}49.3 \\
(19.9)\end{array}$} & \multicolumn{2}{|c|}{$\begin{array}{c}53.3 \\
(18.1)\end{array}$} & $\begin{array}{c}\chi^{2}(2)=113.0 \\
p<.01\end{array}$ \\
\hline & $\begin{array}{c}35.4 \\
(18.8)\end{array}$ & $\begin{array}{c}52.4 \\
(20.8)\end{array}$ & $\begin{array}{c}48.5 \\
(19.8)\end{array}$ & $\begin{array}{c}52.5 \\
(20.0)\end{array}$ & $\begin{array}{c}52.4 \\
(17.8)\end{array}$ & $\begin{array}{c}55.2 \\
(18.8)\end{array}$ & $\begin{array}{c}\chi^{2}(5)=130.7 \\
p<.01\end{array}$ \\
\hline \multirow{2}{*}{$\begin{array}{l}\text { Visible } \\
\text { tattoos } \\
\text { harmful }\end{array}$} & \multicolumn{2}{|c|}{$\begin{array}{c}6.74 \\
(1.65)\end{array}$} & \multicolumn{2}{|c|}{$\begin{array}{c}6.24 \\
(1.73)\end{array}$} & \multicolumn{2}{|c|}{$\begin{array}{c}6.16 \\
(1.46)\end{array}$} & $\begin{array}{l}\chi^{2}(2)=26.8 \\
p<.01\end{array}$ \\
\hline & $\begin{array}{c}6.78 \\
(1.61)\end{array}$ & $\begin{array}{c}5.75 \\
(2.49)\end{array}$ & $\begin{array}{c}6.23 \\
(1.79)\end{array}$ & $\begin{array}{c}6.28 \\
(1.47)\end{array}$ & $\begin{array}{c}6.16 \\
(1.49)\end{array}$ & $\begin{array}{c}6.17 \\
(1.44)\end{array}$ & $\begin{array}{l}\chi^{2}(5)=31.9 \\
p<.01\end{array}$ \\
\hline
\end{tabular}

Notes: The first row of each variable indicates the mean (s.d.), by tattoo status, for whether subjects care what others think about them (first row), their percentage of friends with tattoos, their estimates of the percentage of tattooed individuals in U.S. population and whether a visible tattoo is harmful in a hiring scenario. The second row of each variable divides the subjects according to whether they are likely or unlikely to get a(nother) tattoo within the next year. See the Appendix for the precise questions and response categories. The last column reports the Kruskal-Wallis test results. 
Table 16: Ordered Probits on Tattoo Status

\begin{tabular}{|c|c|c|}
\hline Variable & (18) & (19) \\
\hline Switching Pair & $\begin{array}{l}.03 * * \\
(.01)\end{array}$ & $\begin{array}{l}.03^{* *} \\
(.01)\end{array}$ \\
\hline 1 CRT correct & $\begin{array}{l}-.19 \\
(.13) \\
\end{array}$ & $\begin{array}{l}-.18 \\
(.14) \\
\end{array}$ \\
\hline 2 CRT correct & $\begin{array}{l}-.12 \\
(.13) \\
\end{array}$ & $\begin{array}{c}-.10 \\
(.14) \\
\end{array}$ \\
\hline 3 CRT correct & $\begin{array}{c}-.36 * * * \\
(.13)\end{array}$ & $\begin{array}{c}.36^{* * *} \\
(.14)\end{array}$ \\
\hline 4 (All) CRT correct & $\begin{array}{c}-.32 * * * \\
(.12) \\
\end{array}$ & $\begin{array}{l}-.25^{*} \\
(.13) \\
\end{array}$ \\
\hline Care what others think & $\begin{array}{c}-.02 \\
(.03)\end{array}$ & $\begin{array}{c}-.02 \\
(.03)\end{array}$ \\
\hline$\%$ friends with tattoos & $\begin{array}{c}.02^{* * * *} \\
(.00)\end{array}$ & $\begin{array}{c}.02^{* * * *} \\
(.00) \\
\end{array}$ \\
\hline \% U.S. pop'n with tattoos & $\begin{array}{l}.005^{* *} \\
(.002)\end{array}$ & $\begin{array}{c}.004 \\
(.003)\end{array}$ \\
\hline Visible tattoos harmful & $\begin{array}{c}-.07 * * * * \\
(.02)\end{array}$ & $\begin{array}{c}-.07^{* * *} \\
(.03)\end{array}$ \\
\hline Risk, Socio-demo controls & No & Yes \\
\hline Threshold 1 & $\begin{array}{c}0.93 \\
(0.25)\end{array}$ & $\begin{array}{c}2.70 \\
(1.00)\end{array}$ \\
\hline Threshold 2 & $\begin{array}{c}2.18 \\
(0.26) \\
\end{array}$ & $\begin{array}{c}4.01 \\
(1.00)\end{array}$ \\
\hline Pseudo $\mathrm{R}^{2}$ & .16 & .19 \\
\hline $\mathrm{N}$ & 1080 & 1047 \\
\hline
\end{tabular}

Notes: Ordered Probit regressions with tattoo status as the dependent measure, equal to 0 if not tattooed, 1 if hidden tattooed and 2 if visibly tattooed. The regressors include the subject's switching pair, indicators for the subject's number of correctly answered CRT questions, the extent to which the subject cares what others think about them, percentage of friends with tattoos, perception about the percentage of tattooed individuals in U.S. population and the extent to which a visible tattoo is perceived to be harmful in a hiring scenario. See the Notes of Table 5 for the risk measure and set of socio-demographic controls. A quadratic for age is also included here to capture the inverted-U relationship between age and the likelihood of having a tattoo. 


\section{Appendix - Instructions for time-preferences experiment and selective survey questions}

You are about to complete a short questionnaire that takes no more than 30 minutes of your time. In addition to the $\$ 1.25$ payment that all participants will receive, and in appreciation for completing the questionnaire, we will pay you another $\$ 1$ within 18 hours of completing the questionnaire. However, if you are willing to wait, you may earn more than $\$ 1$. Below is a table with 10 pairs each consisting of two options. Throughout all 10 pairs, the option on the left-hand side (Option A) always remains the same: receive $\$ 1$ within 18 hours. The option on the righthand side (Option B) always involves receiving the indicated payment in three weeks (21 days from today). What changes between the 10 pairs is the amount you will receive in three weeks if you choose Option B. This amount increases from one pair to the next. For each pair of options, you are requested to select the option you prefer. Upon completion of the questionnaire, one of the 10 pairs of options will be randomly selected and the option you chose from this pair will be paid to you as stated in this option. For example, if Pair 6 is selected randomly, then you will receive either $\$ 1$ within 18 hours or $\$ 1.45$ in 3 weeks according to the option that you selected. Please go ahead and select one option from each of the 10 pairs.

Pair 1

Option A (payment in 18 hours) $\$ 1.00$ in 18 hours

O Option B (payment in 3 weeks) $\$ 1.00$ in 3 weeks

Pair 2

Option A (payment in 18 hours) $\$ 1.00$ in 18 hours

Option B (payment in 3 weeks) $\$ 1.05$ in 3 weeks

\section{Pair 3}

Option A (payment in 18 hours) $\$ 1.00$ in 18 hours

Option B (payment in 3 weeks) $\$ 1.10$ in 3 weeks

\section{Pair 4}

Option A (payment in 18 hours) $\$ 1.00$ in 18 hours

Option B (payment in 3 weeks) $\$ 1.20$ in 3 weeks

\section{Pair 5}

Option A (payment in 18 hours) $\$ 1.00$ in 18 hours

Option B (payment in 3 weeks) $\$ 1.30$ in 3 weeks 
Pair 6

Option A (payment in 18 hours) $\$ 1.00$ in 18 hours

Option B (payment in 3 weeks) $\$ 1.45$ in 3 weeks

Pair 7

Option A (payment in 18 hours) $\$ 1.00$ in 18 hours

Option B (payment in 3 weeks) $\$ 1.65$ in 3 weeks

Pair 8

Option A (payment in 18 hours) $\$ 1.00$ in 18 hours

Option B (payment in 3 weeks) $\$ 1.90$ in 3 weeks

Pair 9

Option A (payment in 18 hours) $\$ 1.00$ in 18 hours

Option B (payment in 3 weeks) $\$ 2.20$ in 3 weeks

Pair 10

Option A (payment in 18 hours) $\$ 1.00$ in 18 hours

Option B (payment in 3 weeks) $\$ 2.50$ in 3 weeks 


\section{Domain-Specific Short-Sightedness Questions}

\section{Financial Domain}

(No Retirement Savings) Which of the following statements best describes your savings for retirement?

O I have no savings or investments whatsoever.

O I put aside money for savings from time to time, but need to do more.

I regularly save and invest money and am on the right track.

(Late Credit Card) How often do you make your credit-card payment late?

Regularly

O Sometimes

O Rarely

O Never

O Prefer not to answer

(Poor Finances) How well do you manage your finances and your debt?

Quite well, they are almost never a concern.

Reasonably well, they are not usually a concern.

Not so well, they are often a concern.

Poorly, they are almost always a concern.

\section{Health Domain}

(Overeat) During the past 3 months, how many times would you say that you ate so much that you didn't feel well?

O 0 times

O 1 time

O 2-3 times

O 4-9 times

10-19 times

O 20 or more times

(Exercise) How often do you exercise?

O daily

O 2-4 days a week

O 1 day a week 
infrequently

O not at all

(Alcohol) How many alcoholic beverages do you consume in a typical week?

○ 0

○ $1-2$

○ 3-6

O $7-12$

O $13-18$

O more than 18

(Smoke) Do you smoke?

O Yes, regularly.

O Yes, occasionally.

No, I used to, but I quit.

O No, I've never been a smoker.

\section{Social Domain}

(Personal) How often do you post personal or private information online? (facebook, twitter, blogs, etc)?

O Never 1

O 2

O 3

O 4

O 5

O 6

○ 7

O 8

O 9

O Daily 10 
(Controversial) How likely/willing are you to post online statements or opinions that could be controversial or offensive to some?

Not at all likely/willing 1

○ 2

O 3

○ 4

○ 5

○ 6

○ 7

○ 8

○ 9

Extremely likely/willing 10

(Good Time) Socially, I want to have a good time now, even if my future might suffer as a result.

Strongly disagree 1

O 2

○ 3

○ 4

○ 5

6

Strongly agree 7

\section{Cognitive Reflection Task (CRT)}

(CRT1) A fast-food vendor sells a combo meal consisting of a hamburger and fries. The cost to the vendor of each combo meal is 210 cents. The hamburger costs 200 cents more than the fries. How much do the fries cost?

Cents:

(CRT2) Spanish moss grows on trees. Suppose the moss doubles the amount of tree that it covers every week. If after 60 weeks the entire tree is covered in moss, how long does it take for the moss to cover half of the tree?

Weeks: 
(CRT3) It takes 5 printers 5 minutes to print out 5 documents. How much time is needed for 100 printers to print out 100 documents?

Minutes:

(CRT4) You're competing in a 5-mile run. In the last mile of the race you pass the person in 96th position. In which position did you finish?

Position:

\section{Seen CRT questions before}

(SeeBefore1)A fast-food vendor sells a combo meal consisting of a hamburger and fries. The cost to the vendor of each combo meal is 210 cents. The hamburger costs 200 cents more than the fries. How much do the fries cost?

I had seen this exact question before and remembered the trick that leads to the solution.

I had seen a version of this question before and remembered the trick that leads to the solution.

O I had seen a version of this question before, but did not remember the trick that leads to the solution.

I had never seen a version of this question before.

(SeeBefore2) Spanish moss grows on trees. Suppose the moss doubles the amount of tree that it covers every week. If after 60 weeks the entire tree is covered in moss, how long does it take for the moss to cover half of the tree?

I had seen this exact question before and remembered the trick that leads to the solution.

I had seen a version of this question before and remembered the trick that leads to the solution.

O I had seen a version of this question before, but did not remember the trick that leads to the solution.

I had never seen a version of this question before.

(SeeBefore3) It takes 5 printers 5 minutes to print out 5 documents. How much time is needed for 100 printers to print out 100 documents?

I had seen this exact question before and remembered the trick that leads to the solution.

I had seen a version of this question before and remembered the trick that leads to the solution.

O I had seen a version of this question before, but did not remember the trick that leads to the solution.

I had never seen a version of this question before. 
(SeeBefore4) You're competing in a 5-mile run. In the last mile of the race you pass the person in 96th position. In which position did you finish?

I I had seen this exact question before and remembered the trick that leads to the solution.

I had seen a version of this question before and remembered the trick that leads to the solution.

O I had seen a version of this question before, but did not remember the trick that leads to the solution.

I had never seen a version of this question before.

Socio-demographic Questions (coded responses in parentheses)

Gender

Male

O Female

Other

Age:

What is the highest level of education you have obtained?

Primary school (1)

O High school (2)

College/University degree (3)

Post-graduate degree (4)

Are you currently employed?

No (1)

Yes, part-time (2)

Yes, full-time (3)

Retired (4)

O Student (5)

In which State do you currently reside? (e.g., North Dakota, Florida)

Please indicate your own monthly after-tax income:

O Under \$500 monthly (1)

O \$500-\$999 monthly (2)

O \$1,000-\$1,999 monthly (3)

O \$2,000-\$3,999 monthly (4)

○ \$4,000-\$5,999 monthly (5) 
O \$6,000-\$7,999 monthly (6)

O \$8,000-\$9,999 monthly (7)

O \$10,000-\$14,999 monthly (8)

O Over $\$ 15,000$ monthly (9)

O Rather not say (10)

Please rate the strength of your religious beliefs:

O None (1)

O 2 (2)

O $3(3)$

O 4 (4)

O $5(5)$

O 6 (6)

O Very strong (7)

How often do you attend a house of worship (e.g., church, mosque, synagogue, temple)?

O Never (1)

Once a year (2)

O Several times a year (3)

O Once a month (4)

O Once a week (5)

O Several times a week (6)

O Daily (7)

Please rate your belief in God:

O No belief (1)

O 2 (2)

O $3(3)$

O $4(4)$

O $5(5)$

O $6(6)$

O Absolute belief (7)

How do you see yourself? Are you generally a person who is fully prepared to take risks or do you try to avoid taking risks? Please select a box on the scale below, where the value 0 means "not at all willing to take risks" and the value 10 means "very willing to take risks".

O 0

○ 1 


$\begin{array}{ll}\text { O } & 2 \\ 0 & 3 \\ 0 & 4 \\ 0 & 5 \\ \bigcirc & 6 \\ 0 & 7 \\ \bigcirc & 8 \\ \bigcirc & 9 \\ \bigcirc & 10\end{array}$

\section{Motives for Tattoo}

For all of your hidden tattoos, which explanations describe why you chose to get the tattoo(s)? Choose all that apply.

- As an expression of individuality.

$\square$ To memorialize a loved one.

$\square$ To remember a particular time in my life.

$\square$ To say something about who I am/ my personal identity.

$\square$ As a political/environmental statement.

$\square$ As a snap or impulsive decision.

$\square$ To create a certain image of me.

$\square$ Most of my friends are tattooed.

$\square$ I belong to a group, a majority of whom are tattooed.

$\square$ I like the way the tattoo looks.

$\square$ Other

For all of your visible tattoos, which explanations describe why you chose to get a tattoo? Choose all that apply.

As an expression of individuality.

$\square$ To memorialize a loved one.

$\square$ To remember a particular time in my life.

$\square$ To say something about who I am/ my personal identity.

口 As a political/environmental statement.

$\square$ As a snap or impulsive decision.

$\square$ To create a certain image of me.

$\square$ Most of my friends are tattooed.

I belong to a group, a majority of whom are tattooed.

$\square$ I like the way the tattoo looks.

$\square$ Other 


\section{Other Questions for the Tattooed Only}

How long did you contemplate your first tattoo before you went ahead and got it done? Choose one.

I didn’t give it much thought, it was done spontaneously.

O A day or two.

Several days.

O A week or more.

O At least a month.

More than a year.

When did you get your most recent tattoo?

Within the past year.

Between 1 and 3 years ago.

O Between 3 and 10 years ago.

O Between 10 and 20 years ago.

O More than 20 years ago.

\section{Questions to Evaluate whether the Tattooed don't care or are unaware}

How important is it to you what others think of you?

Not important at all (1)

○ (2)

○ 3 (3)

○ 4 (4)

○ (5)

$6(6)$

Very important (7)

What percentage of your friends have one or more tattoos?

If you had to guess, what percentage of people in the United States have one or more tattoos?

Imagine an acquaintance of yours is applying for an advertised job opening as a hotel manager. The job ad states that the qualified applicant will have: extensive experience in hotel operations; computer literacy and experience in Windows operating system, database management and financial software; a college/university degree in a related discipline preferred; strong interpersonal skills and the ability to remain calm and courteous at all times; be highly responsible and reliable. Suppose your acquaintance has many of these basic qualifications. Consider each of 
the following factors separately. How much do you think each one will help or hinder your acquaintance in getting hired? Your acquaintance is/has:

\begin{tabular}{|c|c|c|c|c|c|c|c|c|c|}
\hline & $\begin{array}{l}\text { Extremely } \\
\text { helpful } \\
\text { (1) }\end{array}$ & (2) & (3) & (4) & $\begin{array}{c}\text { Neither } \\
\text { helpful } \\
\text { nor } \\
\text { harmful } \\
\text { (5) }\end{array}$ & (6) & (7) & (8) & $\begin{array}{l}\text { Extremely } \\
\text { harmful } \\
\text { (9) }\end{array}$ \\
\hline $\begin{array}{l}\text { Limited experience in } \\
\text { hotel operations (1) }\end{array}$ & $\mathrm{O}$ & $\mathrm{O}$ & O & $\mathrm{O}$ & O & O & $\mathrm{O}$ & O & O \\
\hline $\begin{array}{l}\text { Familiarity with } \\
\text { Windows, but no } \\
\text { previous experience } \\
\text { with database } \\
\text { management or } \\
\text { financial software (2) }\end{array}$ & 0 & O & 0 & O & 0 & 0 & 0 & 0 & O \\
\hline $\begin{array}{c}\text { A high school education } \\
\text { only (3) }\end{array}$ & 0 & O & 0 & O & 0 & 0 & 0 & 0 & O \\
\hline $\begin{array}{l}\text { An unfriendly } \\
\text { personality (4) }\end{array}$ & 0 & O & 0 & O & 0 & 0 & 0 & 0 & O \\
\hline $\begin{array}{l}\text { Unenthusiastic } \\
\text { references (5) }\end{array}$ & 0 & O & 0 & O & 0 & O & 0 & 0 & O \\
\hline A criminal record (6) & $\mathrm{O}$ & $\mathrm{O}$ & O & $\mathrm{O}$ & O & $\mathrm{O}$ & O & $\mathrm{O}$ & $\mathrm{O}$ \\
\hline Visible tattoos (7) & O & O & O & O & O & O & O & O & O \\
\hline $\begin{array}{l}\text { Visible piercings (other } \\
\text { than ear piercings) (8) }\end{array}$ & O & $\mathrm{O}$ & O & $\mathrm{O}$ & O & O & O & O & $\mathrm{O}$ \\
\hline $\begin{array}{l}\text { Physically unattractive } \\
\text { (9) }\end{array}$ & $\mathrm{O}$ & $\mathrm{O}$ & O & $\mathrm{O}$ & O & O & O & $\mathrm{O}$ & $\mathrm{O}$ \\
\hline Overweight (10) & 0 & $\mathrm{O}$ & 0 & $\mathrm{O}$ & 0 & $\mathrm{O}$ & 0 & $\mathrm{O}$ & 0 \\
\hline Gay/Lesbian (11) & 0 & 0 & 0 & 0 & 0 & 0 & 0 & 0 & 0 \\
\hline
\end{tabular}

